\title{
Geoquímica y mineralogía de los jales del distrito minero Tlalpujahua-El Oro, México, y sus implicaciones de impacto ambiental
}

\section{Pedro Corona-Chávez ${ }^{1, *}$, Roberto Maldonado², Yann René Ramos-Arroyo ${ }^{3}$, Jasinto Robles-Camacho ${ }^{4}$, Rufino Lozano-SantaCruz ${ }^{2}$ y Mónica Martínez-Medina ${ }^{5}$}

\author{
${ }^{1}$ Universidad Michoacana de San Nicolás de Hidalgo, Instituto de Investigaciones Ciencias de la Tierra, \\ Edificio U, Ciudad Universitaria, Morelia, 58020, México. \\ ${ }^{2}$ Universidad Nacional Autónoma de México, Instituto de Geología, Circuito interior Ciudad Universitaria, 04510, México. \\ ${ }^{3}$ Universidad de Guanajuato, Departamento de Hidráulica y Geomática, Av. Juárez 77, Centro, Guanajuato, 36000, México. \\ ${ }^{4}$ Instituto Nacional de Antropologia e Historia, Centro INAH Michoacán, Francisco I. Madero Oriente 799. Col. Centro, Morelia, 58000, México. \\ ${ }^{5}$ Universidad Michoacana de San Nicolás de Hidalgo, Posgrado en Geociencias y Planificación del Territorio, \\ Edificio U, Ciudad Universitaria, Morelia, 58020, México. \\ *pcorona@umich.mx
}

\section{RESUMEN}

Los depósitos de jales del distrito minero de Tlalpujahua y El Oro (DIMITO) fueron apilados sobre laderas y cañadas con un sistema de drenaje activo y cubriendo un basamento constituido por calizas carbonosas y lutitas \pm andesitas que constituyen la roca encajonante de las vetas auríferas de tipo epitermal. Su morfología actual muestra profundos canales y cárcavas de erosión y se ha estimado una pérdida de material $>27-34 \%$ de su volumen original. Se presentan los resultados de un estudio cartográfico de cinco depósitos de jales que fueron abandonados hace $\sim 68$ años, así como la caracterización mineralógica y geoquímica de 12 perfiles y 48 muestras representativas. Los jales están constituidos, en general, por una matriz limo-arenosa calcárea que contiene abundantes clastos líticos. Su pH es ligeramente alcalino de 7.5 a 8.5 y muestran una baja conductividad eléctrica $<80 \mu \mathrm{S} / \mathrm{cm}$. Están conformados por fragmentos de cuarzo ( $\geq 53-68 \%)$, seguido de líticos (7-20\%), calcita ( $\geq 12 \%)$, silicatos (9-11\%), FeTi-óxidos $(\geq 2-3 \%)$ y sulfuros y sulfosales ( $\leq 2 \%)$. Su composición química varía de $\mathrm{SiO}_{2}(56-92 \%), \mathrm{Al}_{2} \mathrm{O}_{3}(>5-13 \%), \mathrm{CaO}+\mathrm{MgO}(\geq 5-11 \%)$, $\mathrm{Fe}_{\text {tot }}(\leq 3-5 \%)$, S total $(0.3-0.91 \%)$ y C total (3.4-6.1\%). Los jales presentan concentraciones promedio de elementos potencialmente económicos: Au (1.2-1.61 g/ton), Ag (28.1-46.8 g/ton), Pb (53.3$145.2 \mathrm{~g} /$ ton) y Zn (155.9-354.5 g/ton), que podrían tener un cierto rendimiento económico. En relación con las concentraciones de los elementos potencialmente tóxicos, los valores del Sb (43.9-72.2 g/ ton) superan ampliamente el LMP de alto riesgo (WHO, 2015) y una docena de muestras de $\mathrm{Pb}$ y $\mathrm{Zn}$ y de As (25.2-40.5 g/ton) muestran valores más altos a los del LMP de bajo riesgo. Sin embargo, éstos valores se observan dispersos y aleatorios en cada perfil, por lo que se discute su potencial tóxico con base en su correlación geoquímicomineralógica y su potencial movilidad. Con el objetivo de estimar el balance ácido-base en los jales del DIMITO, se realizó un modelo matemático de normalización (reducción de Gauss) de los elementos mayores y su relación con los minerales normativos y su potencial tóxico. Se encontró que la mineralogía representa un potente indicador en el análisis de residuos mineros y su potencial tóxico, así como en general que los jales mostraron un bajo riesgo en la generación de drenaje ácido de mina. Sin embargo, se discuten el uso y manejo de la cobertura natural y su relación con los residuos y obras mineras del DIMITO.

Palabras clave: geoquímica; mineralogía; jales; drenaje ácido; distrito minero Tlalpujahua y El Oro; México.

\begin{abstract}
The tailing dumps of the mining district of Tlalpujahua and El Oro (DIMITO) were stacked on the active drainage system and covering a basement consisting of carbonaceous limestones and shales \pm andesites, which constitute the host rock of the epithermal Au vein-type deposit. This geomorphological setting shows deep channels and gullies of erosion and it has been estimated a loss of material $>27-34 \%$ of its original volume. We present mapping of five tailing dumps that were placed $\sim 68$ year ago as well as the mineralogical and geochemical characterization of 12 profiles and 48 samples. Tailings are essentially siliceous-calcareous slime with clasts. Their $\mathrm{pH}$ is slightly alkaline from 7.5 to 8.5 and they show low conductivity $<80 \mu \mathrm{S} / \mathrm{cm}$. They are constituted by abundant quartz ( $\geq 53-68 \%)$, lithics (7-20\%), calcite ( $\geq 12 \%)$, silicates (9-11 $\%), F e$-Ti oxides ( $\geq 2-3 \%$ ) and sulphides and sulphosalts ( $\leq 2 \%)$. Bulk compositions are characterized by $\mathrm{SiO}_{2}$ (56-92\%), $\mathrm{Al}_{2} \mathrm{O}_{3}(>15-13 \%)$, $\mathrm{CaO}+\mathrm{MgO}(\geq 5-11 \%), \mathrm{Fe}_{\text {tot }}(\leq 3-5 \%), S(0.3-0.91 \%)$, and C (3.4-6.1 \%). DIMITO tailings show values of Au (1.2-1.61 g/ton), Ag (28.1-46.8 $\mathrm{g} /$ ton ), $\mathrm{Pb}$ (53.3-145.2 $\mathrm{g} /$ ton) and $\mathrm{Zn}$ (155.9-354.5 g/ton), suggesting that they could still have some economic recovering. In relation to the concentrations of the potentially toxic elements, the values of $\mathrm{Sb}(27.3-72.2 \mathrm{~g} /$ ton) significantly exceed high risk of the LMP (WHO, 2015), and a dozen samples of $P b$ and $Z n$ and $A s$ (25.2-40.5 g/ton) show higher values than low-risk of the LMP. However, these values are scattered and random in each profile, so its toxic potential is discussed based on its mineralogicalgeochemical correlation and its potential mobility. In order to estimate the acid-base accounting (ABA) of the DIMITO, we carried out a mathematical model based from the Gauss-reduction normalization of the geochemical data and their relationships with normative mineralogy. We
\end{abstract}


found that the mineralogy represents a powerful proxy for the diagnostic of the toxic potential of the waste mines and that in general the tailings show not risk of acide mine drainage generation. However, we discuss the environment impact of the tailing dumps and the relationships with the actual land use of the DIMITO.

Key words: geochemistry; mineralogy; mine tailings; acid mine drainage; Tlalpujahua-El Oro Mining District; Mexico.

\section{INTRODUCCIÓN}

Décadas de estudios geoquímicos realizados en diversos depósitos de residuos mineros o jales en todo el mundo (Jambor, 1994; Blowes et al., 2003; Lottermoser, 2010; Lindsay et al., 2015), señalan que uno de los principales retos para evaluar el riesgo de la dispersión de elementos potencialmente tóxicos (EPT), se refiere a que los jales comúnmente muestran una amplia y aleatoria variabilidad en su composición geoquímica y mineralógica, por lo que en muchos casos es única para cada distrito minero. La composición de un jal generalmente corresponde con la combinación de todas las variables intrínsecas de su contexto geológico, así como con los diversos procesos metalúrgicos utilizados. A pesar de la aleatoriedad geoquímica de los jales, también existe un relativo consenso que revela un recurrente aumento del potencial de toxicidad, en relación con un alto contenido de sulfuros ( $\geq 2-4$ \%vol; sulfidic mine wastes; Jambor, 1994; Jamieson, 2011). Las reacciones complejas e incongruentes de intemperismo y oxidación de un jal ocasionan una notable inestabilidad química de los sulfuros y en particular de la pirita $\left(\mathrm{FeS}_{2}\right)$, potenciando la formación de un sistema químico productor de acidez (i.e. generación de $\mathrm{H}^{+}$), el cual puede estar asociado con iones de sulfato $\left(\mathrm{SO}_{4}^{-2}\right)$ y hierro $\left(\mathrm{Fe}^{+2} / \mathrm{Fe}^{+3}\right)$ en un sistema de soluciones ácidas, conocidas como Drenaje Ácido de Mina (DAM; Blowes y Jambor, 1994; Moncur et al., 2005; Blowes et al., 2014), que a su vez favorece la movilidad en solución de los EPT en un sistema hidrológico (Plumlee, 1999). En contraparte, durante el mismo proceso de intemperismo de un jal se llevan a cabo otro tipo de reacciones que pueden generar una relativa neutralización, ya sea por el consumo de iones $\mathrm{H}^{+} \mathrm{o}$ incluso, si su proporción es dominante, pueden generar un sistema no-ácido o alcalino (Jambor y Blowes, 1998; Hageman et al., 2015). En todo caso, el balance de las reacciones de acidez y neutralización de intemperismo en los jales, son atribuidas a la desestabilización de los minerales primarios, ya sea como formadores de roca (silicatos, carbonatos) o inherentes al depósito mineral (ganga o mena), los cuales dan lugar a la formación de minerales secundarios, que pueden precipitar, inhibir y/o neutralizar el sistema durante los procesos de intemperismo (Jambor 2003; Paktunc, 1999; Jamieson et al., 2015). En consecuencia, la comprensión del potencial tóxico de un depósito de residuos mineros se logra con base en una descripción detallada de los minerales y su correlación con la composición geoquímica. Por otro lado, una creciente base de datos geoquímico-mineralógicos y de su potencial tóxico, ha dado lugar a ensayos estadísticos y de modelado numérico (Paktunc 2003; Jambor et al., 2004; Bouzahzah et al., 2014). De este modo, se han logrado establecer algunas hipótesis de predicción en términos de Price (2009), que considera el balance de las reacciones ácido-base de un residuo minero (Acid-Base Accounting; ABA), como una herramienta útil para proponer algunas estrategias de manejo de los residuos mineros (Lottermoser, 2017).

El distrito minero de Tlalpujahua y El Oro (DIMITO) se ha caracterizado por una riqueza histórica de oro y plata relacionada a un sistema de vetas epitermales (Flores, 1920; Camprubí et al., 2003; Bustamante-García 2007). Sus recursos mineros han sido extraídos por más de cinco siglos y durante diversos periodos de extracción se han generado millones de toneladas de residuos mineros sulfúreos (UribeSalas, 2008; Corona-Chávez et al., 2010). Con base en estudios previos de cartografía (Corona-Chávez y Uribe-Salas, 2009; Martínez-Medina, 2009), se observa que los depósitos de jales fueron acumulados sobre cañadas con un sistema de drenaje activo. Actualmente su morfología muestra profundos canales y cárcavas de erosión, revelando una evidente remoción fluvial del material. Por medio de un cálculo de la densidad de drenaje, asistido por un SIG, en comparación con datos históricos de producción de jales (Uribe-Salas 2008), se ha estimado una pérdida entre el $27 \%$ y $34 \%$ de su volumen original (CoronaChávez et al., 2010). Posteriormente, otros estudios han documentado el deslave histórico de "Las Lamas" ocurrido en 1937 (Bernal-Navarro, 2012; Macías-Vázquez et al., 2015; Sánchez-Núñez et al., 2015). Desde el punto de vista geoquímico, Corona-Chávez et al. (2010) presentan una descripción de campo y algunos resultados geoquímicos preliminares de elementos mayores. Recientemente, Morales et al. (2016) discuten la correlación de algunos elementos químicos con las propiedades magnéticas de los jales. Sin embargo, hasta el momento no se cuenta con una descripción detallada de la mineralogía y geoquímica de elementos en traza de los jales del DIMITO.

En este artículo se presenta la caracterización física de campo, la descripción de la composición mineralógica, así como la correlación geoquímica de elementos mayores y en traza de 48 muestras colectadas en 12 perfiles, así como de muestras aisladas representativas de jales y terreros del DIMITO. Se discute la influencia de la erosión y el clima en los procesos de oxidación e intemperismo, así como la relativa estabilidad de los jales del DIMITO. Finalmente, se implementa un modelo matemático algébrico para el cálculo del ABA (Paktunc, 1998; Paktunc et al., 2004), como una herramienta útil para discutir el potencial riesgo y la movilidad de los EPT de los jales del DIMITO.

\section{LOCALIZACIÓN Y MARCO GEOLÓGICO DEL DIMITO}

El distrito minero de Tlalpujahua y El Oro (DIMITO) está localizado en los límites de los Estados de México y Michoacán, entre las coordenadas geográficas $19^{\circ} 52^{\prime}, 19^{\circ} 45^{\prime}$ de latitud norte y $100^{\circ} 05^{\prime}$, $100^{\circ} 20^{\prime}$ de longitud oeste y comprende un área aproximada de $230 \mathrm{~km}^{2}$ (Figura 1). Las ciudades más importantes son El Oro de Hidalgo y Tlalpujahua de Rayón, las cuales distan alrededor de 7 km una de la otra. La altitud promedio es 2,520 m s.n.m. El clima es templado sub-húmedo con lluvias en verano (García, 1998). La precipitación media anual es de $884 \mathrm{~mm}$, sin embargo, los meses más lluviosos son de junio a septiembre, precipitando en forma torrencial $\sim 67 \%$ de la lluvia total (Martínez-Medina, 2009). El DIMITO se encuentra dentro de la subcuenca del Alto Lerma. Los ríos principales: Tlalpujahua, San Miguel y Tultenango son permanentes, mientras que el resto de los arroyos drenan únicamente durante la época de lluvias.

La distribución de las unidades geológicas del DIMITO es compleja (Figura 1). La secuencia más antigua o basamento se caracateriza por una secuencia volcánico-sedimentaria del Jurásico superior-Cretácico inferior perteneciente al terreno Guerrero (Campa y Coney, 1983; Centeno-García et al., 2003), la cual en el área de estudio está constituida principalmente por la intercalación de una secuencia silíceopelítica (Tlalpujahuilla) y calcáreo-pelítica (Dos Estrellas y Remedios) asociada con algunos derrames volcánicos (El Carmen). Esta secuencia se encuentra sobreyacida por conglomerados continentales del Eoceno (De la Teja-Segura et al., 2000) y una serie de unidades volcánicas félsicas (Fries et al., 1965; Pantoja-Alor, 1994) y derrames andesíticobasálticos del Mioceno-Plioceno relacionadas al Cinturón Volcánico Transmexicano (Hernández-Bernal et al., 2016). La cartografía geológico-minera en el DIMITO cuenta con antecedentes desde el siglo XIX 


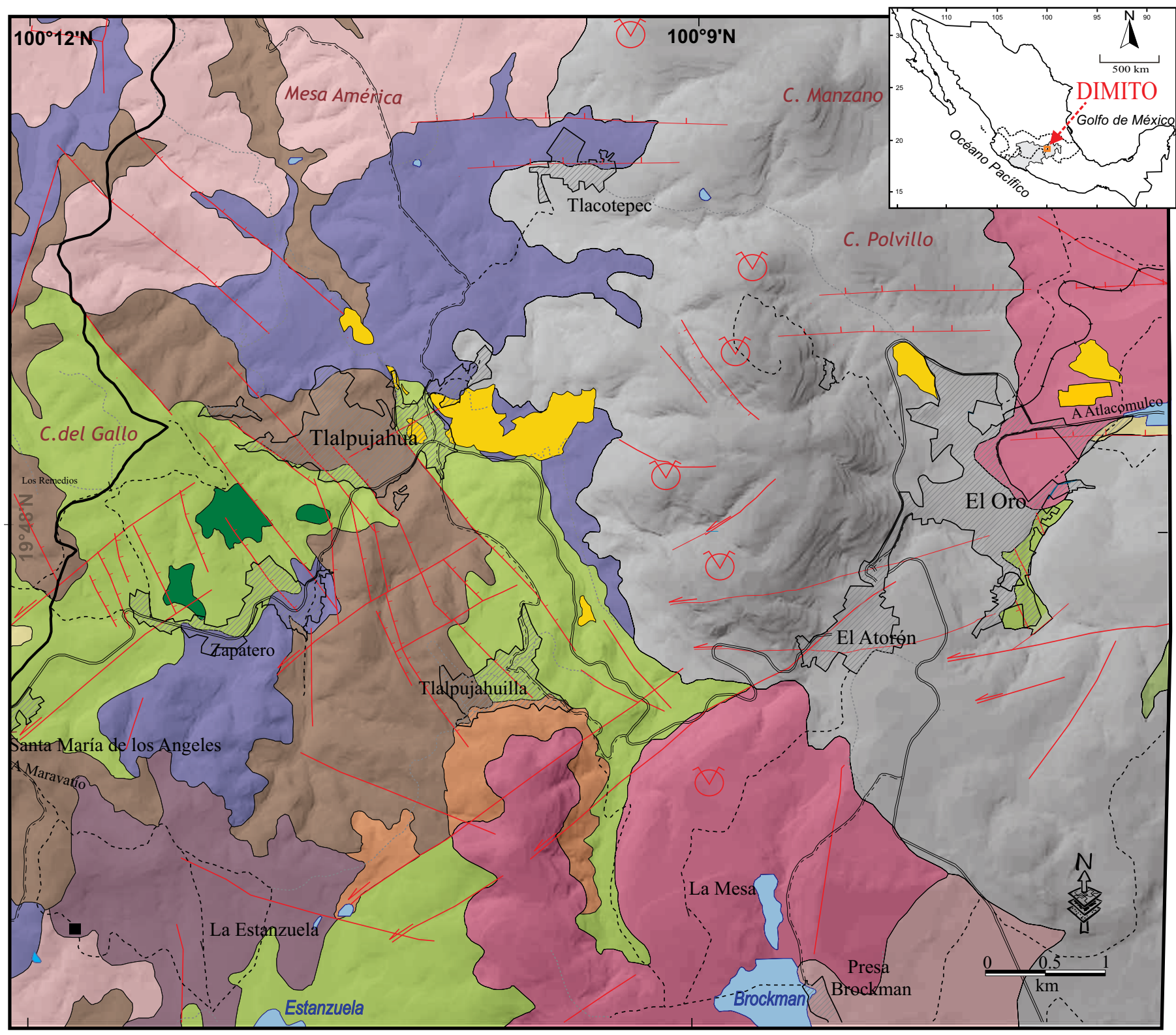

\section{LEYENDA}

\section{Terreno Guerrero}

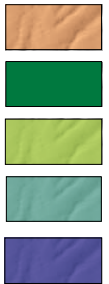

Brechas polimícticas (Eoceno)

Calizas y margas masivas Remedios (K-Cz)

Secuencia calcáreo-pelitica Dos Estrellas (K-CzLu)

Secuencia silíceo-pelitica Tlalpujahuilla (JK-Vs)

Metavolcanicos El Carmen (JK-Vs)

\section{CVTM}

Fluvio-lacustre (Cuaternario)

Basaltos (Plio-Cuaternario)

Andesitas Somera (Mioceno; $2.3 \mathrm{Ma}$ )

Ignimbritas América (Mioceno; $4 \mathrm{Ma}$ )

Andesitas Angangueo (Mioceno; 18-24 Ma)
Depósito de jales

\& Centro Eruptivo

y Falla normal

\& Falla Lateral

D Cuerpos de agua

Poblaciones

Figura 1. Mapa geológico del DIMITO (modificado de Corona-Chávez y Uribe-Salas, 2009). Abreviaciones: Cinturón Volcánico Transmexicano (CVTM); Jurásico (J); Cretácico (K); Plioceno (Pli); Cuaternario (Q); Caliza (Cz), Volcánico-sedimentario (Vs). 
por Burkart (1869); sin embargo, la carta de base más importante fue realizada por Flores (1920), misma que fue actualizada por Silva-Ortiz y Salgato-Soto, (1988), De la Teja-Segura et al. (1999) y Corona-Chávez y Uribe-Salas (2009; Figura 1).

\section{DEPÓSITOS MINERALES DEL DIMITO}

Los depósitos minerales del DIMITO están constituidos por un sistema de vetas que ha sido clasificado como un depósito auroargentífero de tipo epitermal y de baja sulfuración (Albinson et al., 2001). El sistema de veta-fallas se distribuye en forma antitética con una orientación promedio de $\mathrm{N} 30^{\circ} \mathrm{W}$ con echados $>70^{\circ}$, mientras que la longitud puede variar entre 100 y 3,500 m (Flores, 1920; De la Teja-Segura et al., 1999; Figura 2). Las vetas se encuentran alojadas en las rocas del basamento cretácico, generalmente en unidades metasedimentarias calcáreas y calcáreo-pelíticas y en menor proporción en rocas metavolcánicas. Los espesores de las estructuras de veta son muy variables desde 0.5 hasta $33 \mathrm{~m}$. Las zonas de alteración típicas son de argilización (sericitización) \pm oxidación \pm silicificación y raramente propilitización. Los minerales económicos o mena consisten de una serie de sulfuros y sulfosales auro-argentíferos complejos asociados a una matriz de ganga constituida esencialmente de cuarzo \pm calcita. De la Teja-Segura et al. (1999) han definido al menos tres etapas de mineralización: 1) pirita-calcopirita-arsenopirita; 2) esfalerita-galenacalcopirita; 3) boulangerita-freigbergita-pirargirita-oro-naumanitaaguilarita-fischesserita-crookesita, oro y plata nativos. Los valores promedio en sus leyes varían entre 4-5 g/ton Au y 225-300 g/ton Ag (Elvir-Aceituno, 1955). Sin embargo, fueron reportadas mineralizaciones que alcanzaron leyes históricas de hasta $0.1-3 \mathrm{~kg} /$ ton de oro y de $2-70 \mathrm{~kg} /$ ton de plata (Uribe-Salas, 2008).

\section{OBRAS, RESIDUOS MINEROS Y JALES EN EL DIMITO}

Aunque se considera que la extracción de metales en el DIMITO comenzó desde la época prehispánica, en realidad las obras mineras industriales iniciaron a fines del siglo XVI, en lo que fue conocido como el "Real de Minas de Tlalpujahua". Durante la época de la Colonia y hasta fines del siglo XVII se explotaron una serie de vetas expuestas (Coronas y Borda), localizadas en el corazón de la actual ciudad de Tlalpujahua. En 1787, en coincidencia con el descubrimiento de la veta San Rafael en El Oro, se alcanzó en toda la región un importante auge hasta 1868. Sin embargo, la etapa de mayor productividad del distrito iniciaría en los albores del siglo XX, cuando se descubrieron bajo el cerro Somera, las estructuras subterráneas de las vetas Verde, Nueva y Negra, las cuales contenían importantes concentraciones de oro y que habrían de ser intensamente explotadas hasta 1938, tiempo en que la actividad declinó en forma abrupta, para cesar por completo en 1949 (Corona-Chávez et al., 2010). Para una primera aproximación visual del impacto de las obras de extracción minera en el DIMITO, en la Figura 2 se presenta la cartografía de más de 35 estructuras de vetas mineralizadas que fueron explotadas utilizando más de 61 obras mineras de extracción (socavónes, tiros). En la Figura 2, también se muestra la distribución de los residuos mineros (jales y terreros), donde los cinco depósitos de jales corresponden sólo a los volúmenes generados durante la última etapa de extracción. Esta etapa inició a partir de 1902 y por medio del método de cianuración se logró una alta recuperación metalúrgica ( $99 \% \mathrm{Au}$ y $\sim 56 \% \mathrm{Ag}$ ), incrementándose de manera exponencial la generación de jales y alcanzando más de $1 \mathrm{Mt}$ /año (Uribe-salas, 2008). Acerca de los jales generados por el método de amalgamación durante la época de la colonia y hasta fines del siglo XIX, aparentemente no queda algún vestigio. Los depósitos eran relativamente pequeños y sus residuos ( $\leq 2,300$ ton/año), fueron directamente descargados a los ríos, en al menos 12 haciendas de beneficio (Uribe-Salas, 2008).

Los antecedentes de estudio geoquímicos de los depósitos de jales del DIMITO se remontan a 1925, cuando se realizaron algunos ensayes químicos y se reportaron leyes de oro y plata promedio de $2.75 \mathrm{~g} / \mathrm{ton}$ y $75 \mathrm{~g} /$ ton respectivamente (Aguilar-Contreras, 1971). Desde esa época han sido sometidos a diferentes pruebas de laboratorio e incluso se hicieron algunas propuestas para su recuperación por medio de una planta metalúrgica piloto; sin embargo, nunca se logró llevar a cabo una inversión a nivel industrial. Recientemente la empresa minera Gold Corp presentó un informe público (Candente, 2014), para el depósito de jales Tiro México (ver en Figura 2), en el que reporta valores económicos similares a Aguilar-Contreras (1971). Por otro lado, recientemente, Morales et al. (2016) realizaron un estudio de la susceptibilidad magnética (SM) de muestras de jales, en el que observan que algunos elementos como el $\mathrm{Fe}$, As y $\mathrm{Pb}$ muestran una buena correlación lineal con sus propiedades físicas, por lo que considera la SM una potencial técnica o proxy para identificar su toxicidad.

\section{ESTRATEGIA DE MUESTREO Y TÉCNICAS ANALÍTICAS}

Se realizó un mapeo detallado de los cinco depósitos de presas de jales del DIMITO (Figura 2, Tabla 1). De oeste a este: i) El Carmen; ii) Cedros; iii) Dos Estrellas; iv) Tiro México; v) El Oro Conalep (La Esperanza). El muestreo de los jales se llevó a cabo en campañas interdisciplinarias de campo colectando muestras durante los años 2006-2008. Se dscribieron 12 perfiles y se colectaron muestras aisladas de jales, considerando una distribución espacial y representatividad geoquímica (Ramos-Arroyo y Siebe-Grabach, 2006). Las estaciones de muestreo se seleccionaron considerando la altitud y tres posiciones al interior del depósito (cima, intermedia y basal), con la finalidad de identificar variaciones durante los procesos de lixiviación. Para cada muestra se describieron y caracterizaron en campo las propiedades físicas como: color, granulometría, $\mathrm{pH}$, conductividad eléctrica, temperatura, nivel de efervescencia de carbonatos (Tabla 2). Siguiendo el método de SiebeGrabach et al. (1996), se colectaron 1-2 kg de cada muestra, las cuales fueron colocadas en una estufa para su secado a una temperatura $\angle 40^{\circ} \mathrm{C}$ y fueron sucesivamente homogeneizadas por el método de cuarteo, separando diversas alícuotas para: i) su análisis granulométrico por medio de un equipo Lasser-Coulter; ii) la determinación mineralógica; y iii) análisis geoquímicos. Se prepararon láminas delgadas para microscopía óptica de luz transmitida y luz reflejada. Para cada muestra se determinó la textura y los porcentajes modales de los minerales primarios (encajonante y mena) y secundarios (Jambor, 1994), así como de los fragmentos líticos. Sucesivamente, se seleccionaron 21 muestras

Tabla 1. Datos de las superficies y espesores mínimo y máximo de las presas de jales del DIMITO (Modificado de Corona-Chávez et al., 2010 y MartínezMedina, 2009).

\begin{tabular}{lrrrrr}
\hline Presa de Jales & \multirow{2}{*}{$\begin{array}{c}\text { Área } \\
\left(\mathrm{m}^{2}\right)\end{array}$} & $\begin{array}{c}\text { Área } \\
(\mathrm{ha})\end{array}$ & $\begin{array}{c}\text { Área } \\
(\%)\end{array}$ & \multicolumn{2}{c}{ Espesor $(\mathrm{m})$} \\
\cline { 6 - 7 } & & & & máximo & mínimo \\
\hline Los Cedros & $394,152.81$ & 39.42 & 63.28 & 35.3 & 12.4 \\
Dos Estrellas & $14,866.47$ & 1.49 & 2.39 & 1.75 & 0.50 \\
Tiro México & $77,682.10$ & 7.77 & 12.47 & 23.7 & 6.4 \\
CONALEP & $113,898.82$ & 11.39 & 18.29 & 2.2 & 1.40 \\
El Carmen & $22,164.02$ & 2.22 & 3.56 & 1.83 & 0.45 \\
Total & $\mathbf{6 2 2 , 7 6 4 . 2 2}$ & $\mathbf{6 2 . 2 9}$ & $\mathbf{1 0 0}$ & - & - \\
\hline
\end{tabular}




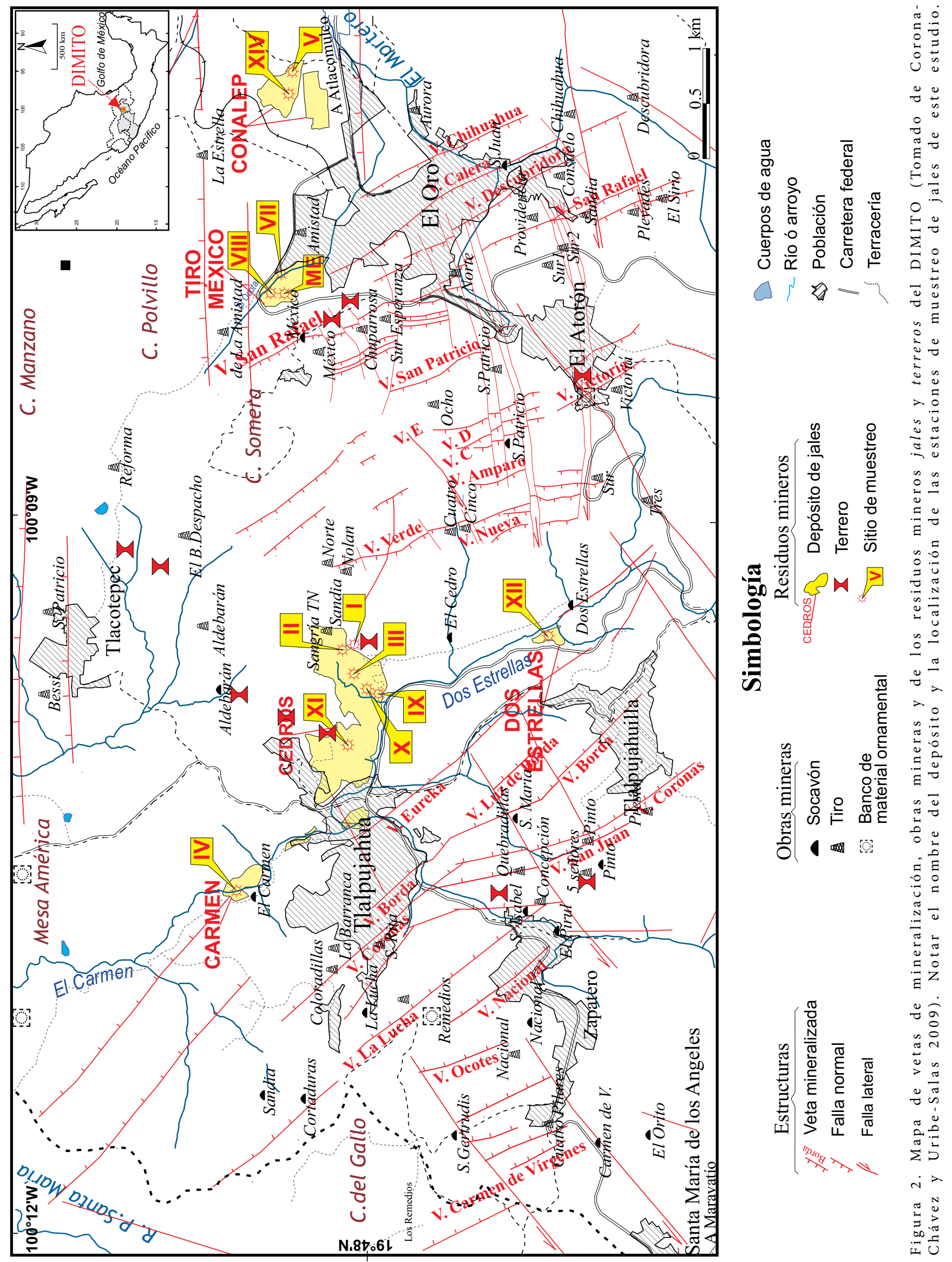


Tabla 2. Localización (coordenadas UTM X; Y) y características físicas de espesor (en centímetros), color, $\mathrm{pH}$, conductividad eléctrica $\left(\mu \mathrm{S} / \mathrm{cm}\right.$ ), temperatura $\left({ }^{\circ} \mathrm{C}\right)$ y porcentajes de $\mathrm{CaCO}_{3}$ de los perfiles de jales del DIMITO. Las etiquetas de las muestras con asterisco corresponden con su análisis químico de elementos mayores (Tabla 4) y en traza (Tabla 5).

\begin{tabular}{|c|c|c|c|c|c|c|c|c|}
\hline \multicolumn{9}{|c|}{ TLALPUJAHUA } \\
\hline Muestra & Espesor & material & Color & Textura & $\mathbf{T}^{\circ} \mathbf{C}$ & $\mathrm{pH}$ & $\mathrm{Ce} \mu \mathrm{S} / \mathrm{cm}$ & $\mathrm{CaCO}_{3}$ \\
\hline \multicolumn{9}{|c|}{ Perfil: Terrero cima $\left(X=378,537 ; Y=2^{\prime} 190,425 ; h=2,628\right.$ m s.n.m. $)$} \\
\hline EI-H1 & $0-30$ & jal-suelo & gris obscuro rojizo & arcillo limoso & 16.9 & 7.15 & 30 & - \\
\hline EI-H2 & $30-70$ & jal & café obscuro rojizo & franco limoso & 16.8 & 6.83 & 20 & - \\
\hline EI-H3 & $>70$ & jal & café & franco arcilloso & 16.6 & 6.39 & 60 & - \\
\hline \multicolumn{9}{|c|}{ Perfil: Terrero cima2 $\left(X=378,528 ; Y=2^{\prime} 190,449 ; h=2,625\right.$ m s.n.m. $)$} \\
\hline EII-H1* & 0 a 1 & jal-suelo & café obscuro & franco arcilloso & 16.0 & 8.17 & 60 & moderada \\
\hline EII-H2 & 1 a 23 & jal & gris Obscuro & franco arcillo limosa & 16.9 & 7.13 & 40 & medio \\
\hline $\mathrm{EII}-\mathrm{H} 3^{*}$ & $23-50$ & jal & gris Obscuro & arcilla limoso & 16.0 & 8.32 & 60 & moderada \\
\hline \multicolumn{9}{|c|}{ Perfil: Cedros basal $\left(X=378,361 ; Y=2^{\prime} 190,457 ; h=2,593\right.$ m s.n.m. $)$} \\
\hline EIII-H1* & $0-2$ & jal & café obscuro grisáceo & franco & 27.1 & 8.14 & 100 & alto \\
\hline EIII-H2* & $2-17$ & jal & café obscuro grisáceo & arcillo limoso & 26.7 & 8.43 & 110 & alto \\
\hline EIII-H3 ${ }^{*}$ & $17-32$ & jal & gris obscuro & franco & 26.4 & 8.4 & 90 & alto \\
\hline EIII-H4 ${ }^{*}$ & $32-80$ & suelo & amarillo pálido & - & 28.5 & 5.89 & 2,090 & medio \\
\hline EIII-H5* & $80-110$ & basal & amarillo pálido & _- & 29 & 5.14 & 570 & medio \\
\hline EIII-H6* & $110-130$ & basal & café amarillento & - & 31.9 & 6.87 & 330 & medio \\
\hline $\begin{array}{c}\text { Perfil: El Carm } \\
\text { EIV-H1 } \\
\text { EIV-H2* } \\
\text { EIV-H3 }\end{array}$ & $\begin{array}{c}\text { mezcla }(X \\
0-13 \\
13-54 \\
54-183\end{array}$ & $\begin{array}{c}77,057 ; Y= \\
\text { jal-suelo } \\
\text { jal } \\
\text { jal }\end{array}$ & $\begin{array}{r}\text { 91,164; } h=2,512 \text { m s.n.m.) } \\
- \\
\text { café obscuro grisáceo } \\
\text { café obscuro grisáceo }\end{array}$ & $\begin{array}{l}\text { franco limoso fino } \\
\text { franco limoso fino }\end{array}$ & $\begin{array}{l}22 . \overline{4} \\
23.6\end{array}$ & $\begin{array}{l}8 . \overline{52} \\
8.4\end{array}$ & $\begin{array}{l}110^{-} \\
110\end{array}$ & $\begin{array}{l}-5-50 \\
25-50\end{array}$ \\
\hline \multicolumn{9}{|c|}{ Perfil: Cerámica basal $\left(X=378,245 ; Y=2^{\prime} 190,369 ; h=2,576\right.$ m s.n.m. $)$} \\
\hline EIX-H1* & $0-15$ & jal & café & franco & 18.4 & 8.45 & 406 & alto \\
\hline $\mathrm{EIX}-\mathrm{H} 2^{*}$ & $15-80$ & jal & café obscuro grisaceo & franco & 18.4 & 8.78 & 166 & alto \\
\hline $\mathrm{EIX}-\mathrm{H} 3^{*}$ & $80-85$ & basal & café amarillento & arcillo limoso & 18.5 & 8.09 & 197 & muy alto \\
\hline $\mathrm{EIX}-\mathrm{H} 4^{*}$ & $85-88$ & jal & gris obscuro & arcilloso medio & 17.6 & 8.49 & 6,780 & medio \\
\hline $\mathrm{EIX}-\mathrm{H} 5^{*}$ & $>88$ & basal & café amarillento & arcillo arenoso & 18.6 & 8.05 & 218 & alto \\
\hline \multicolumn{9}{|c|}{ Perfil: Cerámica basal2 $\left(X=378,246 ; Y=2^{\prime} 190,364 ; h=2,575\right.$ m s.n.m. $)$} \\
\hline EX-H1 & $0-180$ & jal & café ligeramente olivo & franco & 18.5 & 8.29 & 1,139 & alto \\
\hline $\mathrm{EX}-\mathrm{H} 2^{*}$ & $180-260$ & jal & café grisaceo obscuro & arcillo limoso & 19 & 8.06 & 113 & alto \\
\hline EX-H3 & $260-261$ & jal & - & - & - & - & - & - \\
\hline $\mathrm{EX}-\mathrm{H} 4^{*}$ & $>261$ & jal & café grisaceo obscuro & migajòn arcillo limoso & 18 & 8.04 & 3,420 & alto \\
\hline \multicolumn{9}{|c|}{ Perfil: Guerrita basal $\left(X=377,942 ; Y=2^{\prime} 190,493 ; h=2,570\right.$ m s.n.m.) } \\
\hline $\mathrm{EXI}-\mathrm{H} 1^{*}$ & $0-10$ & suelo & gris muy obscuro & arcillo limoso & 18.7 & 8.32 & 76.2 & alto \\
\hline $\mathrm{EXI}-\mathrm{H} 2^{*}$ & $10-38$ & jal & café grisáceo & migajón limoso & 19.6 & 8.66 & 78.4 & alto \\
\hline EXI-H3* & $38-42$ & jal & gris obscuro & migajón arcillo limoso & 18.4 & 9.03 & 67.5 & alto \\
\hline EXI-H4* & $42-190$ & jal & café & arcilloso medio & 19.5 & 8.87 & 1,728 & alto \\
\hline EXI-H5* & $190-220$ & basal & café amarillento & arcilloso medio & 19.7 & 7.4 & 3,960 & bajo \\
\hline EXI-H6* & $>220$ & basal & gris obscuro & roca & 18.8 & 6.71 & 1,530 & medio \\
\hline \multicolumn{9}{|c|}{ Perfil: Cedros intermedio $\left(X=378,691 ; Y=2^{\prime} 189,202 ; h=2,602\right.$ m s.n.m. $)$} \\
\hline EXII-H1 $1^{*}$ & $0-3$ & jal/suelo & café grisáceo obscuro & arena migajosa & 18.6 & 7.14 & 35 & - \\
\hline EXII-H2 & $3-37$ & suelo & café obscuro amarillento & migajón arcillo arenoso & 18.7 & 8.14 & 43.2 & - \\
\hline EXII-H3* & $37-120$ & jal & café ligeramente amarillento & arena & 19 & 7.82 & 31.1 & alta \\
\hline EXII-H $4^{*}$ & $>120$ & jal & café & arcilla arenosa & 20 & 7.65 & 50.8 & media \\
\hline \multicolumn{9}{|c|}{ Perfil: Cedros intermedio2 ( $X=378,251 ; Y=2^{\prime} 190,450 ; h=2,610$ m s.n.m.) } \\
\hline EXIII-H1* & - & jal & café & arcillo arenoso & 18.2 & 8.13 & 1,483 & muy alta \\
\hline EXIII-H2 & - & jal & café & arcilloso medio & 18.4 & 8.3 & 6,310 & muy alta \\
\hline EXIII-H3 & - & jal & café ligeramente olivo & arcilloso medio & 18.2 & 7.73 & 12.58 & muy baja \\
\hline EXIII-H4 $4^{*}$ & - & jal & gris obscuro & arcilloso medio & 18.1 & 8.39 & 282 & muy baja \\
\hline
\end{tabular}

de jal con los mayores contenidos modales de minerales opacos (óxidos, sulfuros, sulfosales, etc.), las cuales fueron sometidas a un proceso de separación de minerales por el método de concentración gravimétrica y magnética (Maldonado-Villanueva, 2008). Para los residuos de minerales metálicos y pesados, se prepararon nuevas secciones pulidas para la determinación específica de sulfuros y óxidos por técnicas de microscopía óptica y electrónica. La determinación de minerales se- cundarios y de alteración se complementó por medio de difracción de rayos $\mathrm{X}$ por el método de polvos utilizando un equipo Siemens XRD 5000 operando en condiciones de radiación $\mathrm{Cu} \mathrm{Ka}(\lambda=1.5406 \AA)$, $40 \mathrm{kV}, 30 \mathrm{~mA}$, paso de $0.01^{\circ} \mathrm{y}$ un intervalo de registro de $2 \theta=5.0-70.0^{\circ}$. Las láminas delgadas seleccionadas fueron pulidas a $1 \mu \mathrm{m}$ y recubiertas con grafito para ser observadas y analizadas por medio de microscopía electrónica de barrido (MEB-EDS), con un equipo JEOL JSM-6400 
Tabla 2 (continuación). Localización (coordenadas UTM X, Y) y características físicas de espesor (en centímetros), color, pH, conductividad eléctrica ( $\mu$ S/cm), temperatura $\left({ }^{\circ} \mathrm{C}\right)$ y porcentajes de $\mathrm{CaCO}_{3}$ de los perfiles de jales del DIMITO. Las etiquetas de las muestras con asterisco corresponden con su análisis químico de elementos mayores (Tabla 4) y en traza (Tabla 5).

\begin{tabular}{|c|c|c|c|c|c|c|c|c|}
\hline \multicolumn{9}{|c|}{ EL ORO } \\
\hline Muestra & Espesor & material & Color & Textura & $\mathbf{T}^{\circ} \mathrm{C}$ & pH & $\mathrm{Ce} \mu \mathrm{S} / \mathrm{cm}$ & $\mathrm{CaCO}_{3}$ \\
\hline \multicolumn{9}{|c|}{ Perfil: Conalep basal $\left(X=382,527 ; Y=2^{\prime} 190,905 ; h=2,685\right.$ m s.n.m. $)$} \\
\hline $\mathrm{EV}-\mathrm{H} 1^{*}$ & $0-9$ & suelo & gris obscuro & arcillo limoso & 20.8 & 8.35 & 48.8 & alta \\
\hline $\mathrm{EV}-\mathrm{H} 2 *$ & $9-52$ & jal & gris obscuro & arcillo limoso & 18.6 & 8.74 & 89 & media \\
\hline EV-H3-A* & $52-94$ & jal & café grisaceo obscuro & Migajón arenoso & 21.9 & 8.81 & 79.2 & alta \\
\hline EV-H3-B & $52-94$ & jal & café grisaceo obscuro & arcillo limoso & 21.4 & 8.68 & 101 & alta \\
\hline EV-H3-C & $52-94$ & jal & gris obscuro & arcillo limoso & 21.0 & 8.68 & 101.4 & alta \\
\hline $\mathrm{EV}-\mathrm{H} 4^{*}$ & $94-103$ & jal & gris obscuro & arcillo arenoso & 21.3 & 8.45 & 108.88 & alta \\
\hline $\mathrm{EV}-\mathrm{H} 5^{*}$ & $103-110$ & jal & gris olivo obscuro & arcillo limoso & 18.9 & 8.04 & 765 & alta \\
\hline EV-H6* & $>110$ & suelo & gris muy obscuro & Migajon arenoso & 19.3 & 7.52 & 395 & baja \\
\hline \multicolumn{9}{|c|}{ Perfil: TiroMéxico basal1 ( $X=381,140, Y=2^{\prime} 190,964 ; h=2,728$ m s.n.m.) } \\
\hline EVII-H1 ${ }^{*}$ & $0-1$ & jal & gris verdoso & Migajón arenoso & 19.6 & 7.93 & 563 & alta \\
\hline EVII-H2 & $1-2$ & suelo & café obscuro & franco & 19.8 & 8.33 & 750 & alta \\
\hline EVII-H3* & $2-12$ & jal & gris obscuro & Migajon arenoso & 19.9 & 8.46 & 197 & alta \\
\hline $\mathrm{EVII}-\mathrm{H} 4^{*}$ & $12-21$ & jal & gris verdoso obscuro & arcilloso medio & 19.6 & 7.97 & 378 & $\sin$ \\
\hline EVII-H5* & $21-29$ & basal & café muy obscuro & arcillo arenoso & 18.8 & 4.48 & 895 & $\sin$ \\
\hline EVII-H6* & $29-39$ & basal & café obscuro & arcillo arenoso & 19 & 6.83 & 342 & baja \\
\hline EVII-H7* & 39 & suelo & café obscuro & - & 19.4 & 7.14 & 240 & baja \\
\hline \multicolumn{9}{|c|}{ TiroMéxico intermedio ( $X=381,140 ; Y=2 ' 190,964 ; h=2,728$ m s.n.m.) } \\
\hline $\mathrm{ME} 07 \mathrm{~m}^{*}$ & & jal & gris obscuro & arcilloso medio & 19.8 & 8.64 & 8,180 & alta \\
\hline ME07c* & & jal & gris obscuro & franco & 20.2 & 7.25 & 469 & alta \\
\hline \multicolumn{9}{|c|}{ Perfil: Tiro México basal2 (X=381,066; $Y=2^{\prime} 191,068 ; h=2,732$ m s.n.m.) } \\
\hline EVIII-H1* & $0-62$ & suelo & gris obscuro & franco & 19.0 & 8.54 & 655 & alta \\
\hline EVIII-H $2^{*}$ & $62-67$ & suelo & café rojizo obscuro & arcillo arenoso & 19.4 & 7.81 & 1,937 & muy baja \\
\hline EVIII-H3* & $67-71$ & jal & gris obscuro & arcilloso medio & 28.7 & 8.36 & 642 & alta \\
\hline EVIII-H4* & $>71$ & basal & café obscuro & arcillo arenoso & 18.2 & 5.73 & 5,680 & $\sin$ \\
\hline \multicolumn{9}{|c|}{ Perfil: Conalep intermedio $\left(X=382,390 ; Y=2^{\prime} 190,936 ; h=2,674\right.$ m s.n.m.) } \\
\hline EXIV-H1 & $0-2$ & jal-suelo & café obscuro grisáceo & arcilloso & 19.2 & 7.8 & 144.9 & alta \\
\hline EXIV-H2* & $2-58$ & jal & café & arcilloso medio & 18.7 & 7.37 & 821 & alta \\
\hline EXIV-H3 & $58-80$ & jal & gris obscuro & arcilloso medio & 18.9 & 7.35 & 1,188 & muy alta \\
\hline EXIV-H4 & $80-100$ & jal & café obscuro grisáceo & arcilloso medio & 19 & 7.53 & 1,570 & alta \\
\hline EXIV-H5 & $100-145$ & jal & café obscuro grisáceo & arcillo limoso & 18.8 & 8.24 & 715 & alta \\
\hline EXIV-H6 & $145-170$ & jal & gris obscuro & arcillo limoso & 18.08 & 8.04 & 1,025 & alta \\
\hline EXIV-H7 & $170-210$ & jal & café obscuro grisáceo & arcillo limoso & 18.5 & 7.86 & 814 & alta \\
\hline EXIV-H8* & $210-220$ & jal & gris obscuro & arcillo limoso & 18.1 & 7.95 & 823 & alta \\
\hline
\end{tabular}

con analizador EDS de la Universidad Michoacana de San Nicolás de Hidalgo. Para la obtención de su composición química, los elementos mayores fueron determinados por el método de fluorescencia de rayos- $\mathrm{X}$ (FRX) en el Instituto de Geología de la Universidad Nacional Autónoma de México (UNAM). El instrumento utilizado fue un espectrómetro secuencial (LFRX -SIEMENS SRS 3000 con tubo de Rh y ventana de Berilio de $125 \mu \mathrm{m})$. Los elementos mayores se determinaron en muestra fundida (Lozano-SantaCruz et al, 1995), mientras que un total de 43 elementos en traza fueron medidos por espectrometría de masas con plasma acoplado inductivamente (ICP-MS), utilizando un equipo Agilent 7500 ce del Instituto de Geología de la Universidad Nacional Autónoma de México (UNAM). Se seleccionaron 12 muestras representativas de cada perfil y por medio de un analizador tipo Leco Modelo C-S-224, se determinaron las concentraciones de azufre y carbono (S/C). La reproducibilidad de los datos se obtuvo por el promedio de las concentraciones y la desviación estándar de múltiples digestiones del material de referencia del US Geological Survey Geochemical Reference Material BHVO-1. Además del muestreo de los perfiles, se colectaron dos muestras aisladas de terreros (vetas Coronas y Borda), para realizar un ensaye de Au y Ag por fusión y apartado con determinación gravi- métrica; dicho estudio se llevó a cabo en el Laboratorio de Química del Departamento de Minas y Metalurgia de la Facultad de Ingeniería de la UNAM. Finalmente, se calculó el potencial de neutralización (PN) y acidez (PA), así como su balance ácido-base (ABA), utilizando los programas Modan y mNP y el método de Paktunc (1998; 1999; 2003) e, incorporando las correcciones para los Al-silicatos aplicadas por Jambor et al. (2004). El cálculo se basa en la composición geoquímica de elementos mayores, incluyendo los valores de azufre y carbono (Paktunc, 1999; Bouzahzah et al., 2014). Se calcula la composición normativa de los minerales: silicatos, carbonatos y sulfuros, los cuales son sucesivamente ponderados, con base en un índice estadístico de capacidad de generación de acidez (Paktunc, 1999; Jambor, 2003).

\section{RESULTADOS}

\section{Cartografía y caracterización física de los jales del DIMITO}

En la Figura 2 se presenta el resultado del mapeo de los residuos mineros (jales y terreros), así como la ubicación georeferenciada de tiros y socavones, mientras que en la Figura 3 se muestran imágenes 

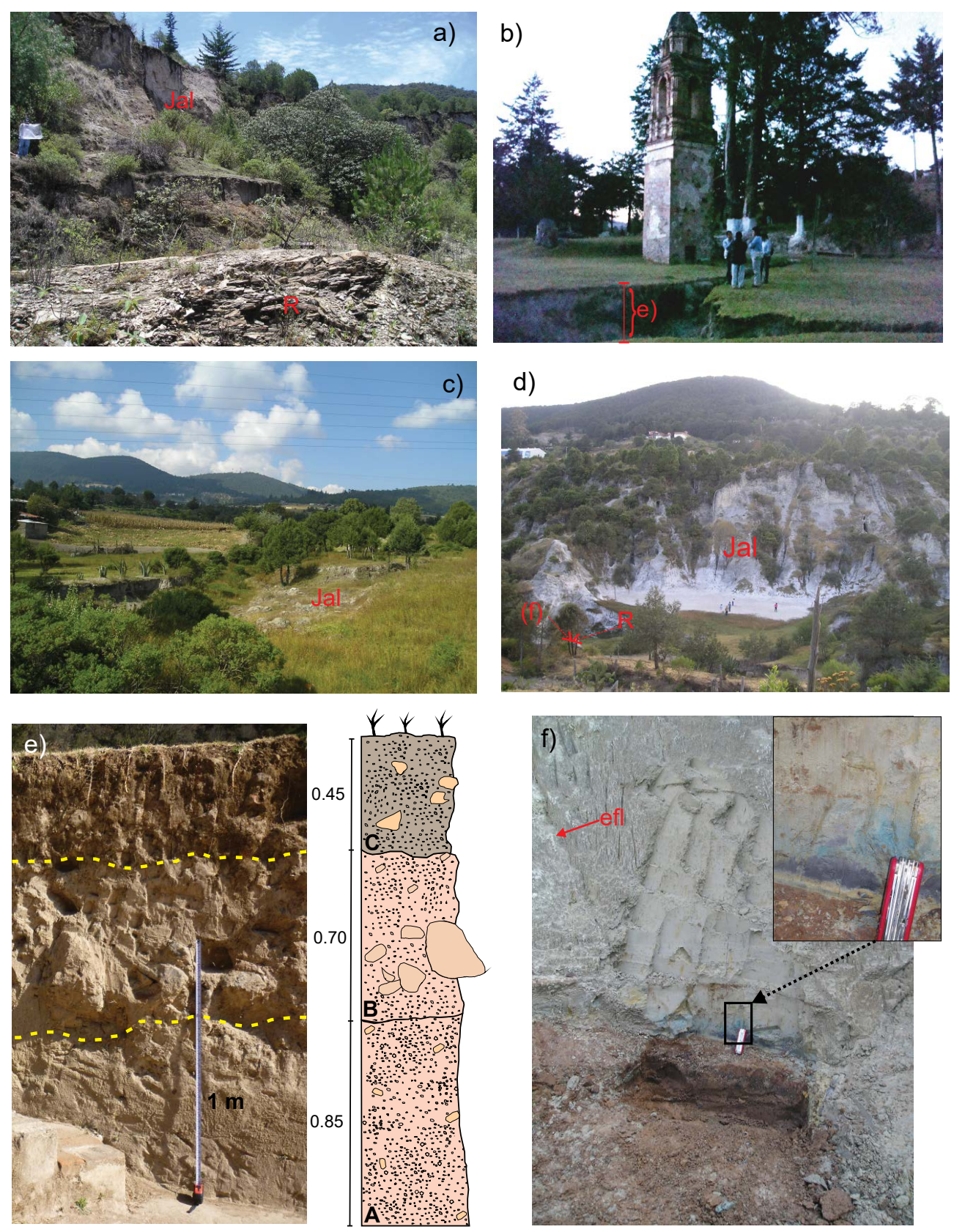

Figura 3. Fotografías de campo de los jales del DIMITO. a) Vista actual de la presa de Jales Cedros de Tlalpujahua; b) Vista de los remanentes de los jales El Carmen, producidos por el deslave del 27 de mayo de 1937 (Bernal-Navarro, 2012; Macías-Vázquez et al., 2015). c) Vista actual de los jales Conalep (Esperanza) en El Oro; d) Vista actual de los Jales Tiro México de El Oro. e) Perfil de la columna de los jales de El Carmen (después de Sánchez-Núñez et al., 2015). Notar la profundidad en cm, de los niveles A, B y C que fueron separados por sus propiedades físicas de campo. f) Perfil EVII-Tiro México. Notar las costras blanquecinas de eflorescencia y el recuadro que muestran el efecto de lixiviados de los jales. Abreviación $\mathrm{R}=$ Sustrato rocoso.

con el aspecto actual de los diversos depósitos de jales. El área total de los jales del DIMITO corresponde a 622,764.22 $\mathrm{m}^{2}$ (Tabla 1). Sin embargo, su distribución en el DIMITO es muy variable: la presa de jales Cedros (Figura 3a), en la región de Tlalpujahua ocupa un total de $63.3 \%$. Los jales de El Carmen, con un área de 2.22 has (3.56 \%), provienen de la antigua presa Cedros, en cuanto se relacionan al alud de fango que se desbordó en 1937 (Figura 3b; Macías-Vázquez et al., 2015). En la región de El Oro se exponen los jales de La Esperanza o CONALEP, con $18.3 \%$ y Tiro México con $12.5 \%$ en el Municipio de El Oro (Figuras $3 \mathrm{c}$ y $3 \mathrm{~d}$ ). El espesor y el volumen de los depósitos varía desde centímetros (El Carmen) hasta $35.3 \mathrm{~m}$ (Cedros), en cuanto dependen de la productividad de cada planta metalúrgica y del apilamiento sobre un "paleo-relieve" natural de la cañada del depósito (Figura 4). Es importante hacer notar que, en correspondencia con un incremento de volumen, los depósitos de jales han dado lugar a geoformas de cárcavas y canales de erosión (Figura 3d), sugiriendo una evidente pérdida de volumen por una singular e intensa erosión fluvial.

En todos los depósitos de jales es posible observar una cobertura heterogénea de vegetación arbustiva y de bosques de cedros, encinos y pinos. El color de los jales varía generalmente de gris a café, pero 


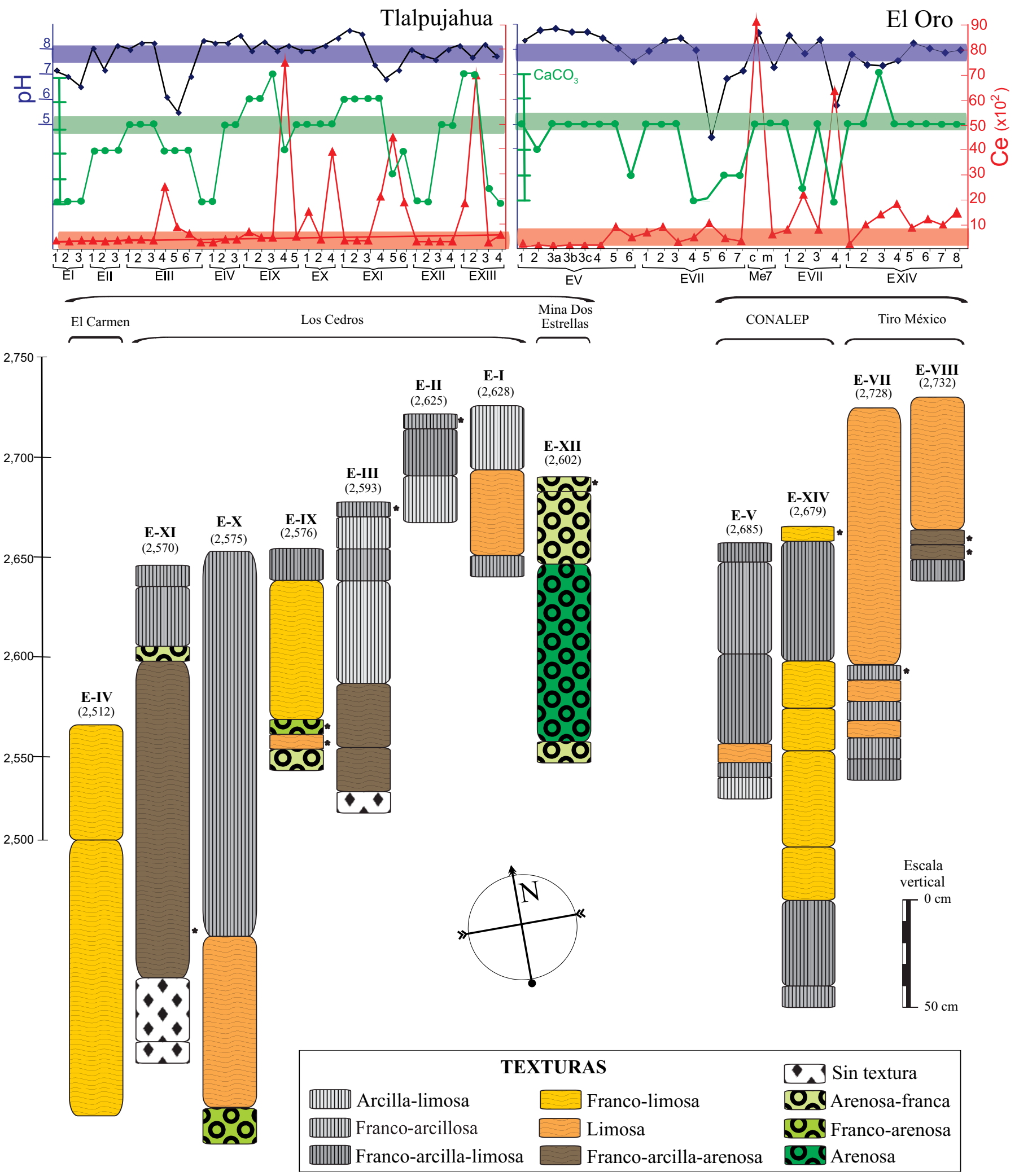

Figura 4. Perfiles estratigráficos medidos y descritos en el DIMITO. Notar la orientación general, la altitud en metros sobre el nivel del mar y la caracterización granulométrica de campo (Siebe-Grabach et al. (1996). Arriba las gráficas de sus propiedades físicas de pH (azul), Ce, conductividad eléctrica (rojo; $\mu \mathrm{S} / \mathrm{cm}$ ) y $\mathrm{CaCO}_{3}$ ó nivel de carbonatación (verde). 
se presentan horizontes delgados amarillo, ocre, naranja y raramente blanco (Figura 3e, Tabla 2). Los jales muestran un aspecto húmedo todo el año, así como es común observar costras blanquecinas de calcita ( \pm sales, e.g. haluros e hidróxidos) formadas por lixiviación, eflorescencia y precipitación de minerals secundarios (Figura 3f). Los jales contienen en forma dispersa, horizontes delgados $(\sim 20 \mathrm{~cm})$ de incrustaciones de carbonatos con espesores milimétricos. En su porción basal, algunas veces ocurren capas centimétricas asociadas a la precipitación de sulfatos de cobre y otras sales, producto de una lixiviación local (recuadro de Figura 3f). En general, los jales muestran un $\mathrm{pH}$ ligeramente alcalino con variaciones de 7.8 a 8.5 (Figura 4); sin embargo, los horizontes basales en tres perfiles (EIII, EVII y EVIII), son ligeramente ácidos (5.1-5.9), lo cual sugiere que los procesos de lixiviación podrían ser aún activos. La conductividad eléctrica es relativamente baja, predominan valores $<200 \mu \mathrm{S} / \mathrm{cm}$ y sólo en pocas muestras alcanza valores $\geq 1,687 \mu \mathrm{S} / \mathrm{cm}$, lo que podría sugerir una baja concentración de minerales solubles y/o una baja presencia de sulfatos. El 90 \% de los horizontes son carbonatados con niveles de efervescencia de medio a alto.

\section{Granulometría y mineralogía de los jales del DIMITO}

\section{Distribución del tamaño de partícula}

La caracterización granulométrica de campo (Tabla 2), indica que la mayoría de los jales del DIMITO presentan texturas al tacto que varían de franco-limosas a franco-arcillosas y en menor proporción algunos horizontes muestran texturas arenosas. Por medio de la medición directa del tamaño de grano con un equipo Lasser-Coulter (Figura 5; Tabla 3), se puede observar que el $80 \%$ de los jales tienden a ser limosos $(4-64 \mu \mathrm{m})$ con variaciones importantes de arcilla $<10 \%$ y con $>7-13$ $\%$ de arenas finas $(64-250 \mu \mathrm{m})$. Es importante hacer notar que en el Distrito de El Oro el tamaño de grano es muy homogéneo (limoso), mientras que en el Tlalpujahua se presenta una mayor heterogeneidad relacionada con variaciones del proceso metalúrgico de molienda.
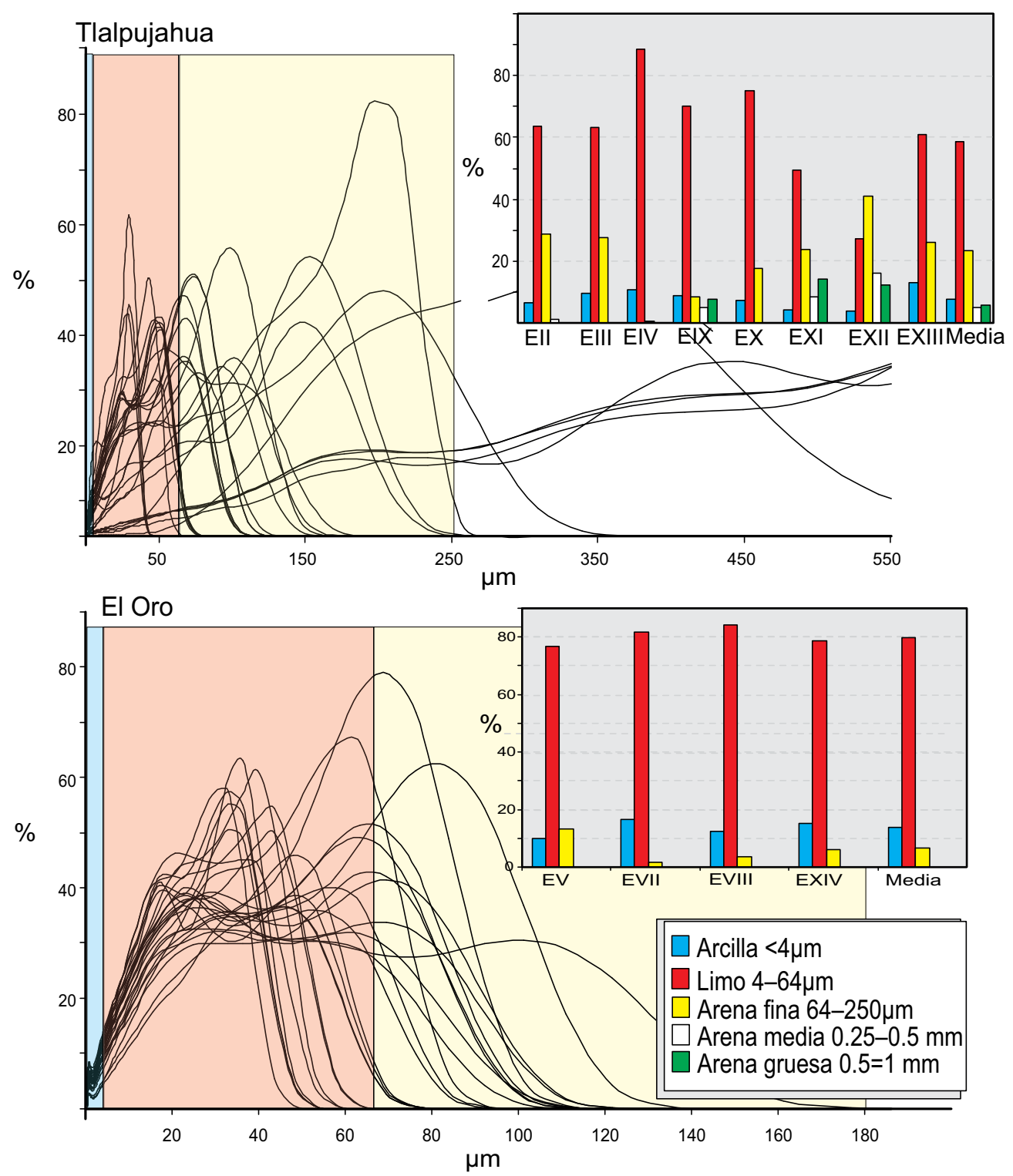

Figura 5. Resultados granulométricos de 71 de los jales del DIMITO, provenientes de los perfiles (Figura 4, Tabla 2) y muestras aisladas, realizados por medio de un detector de laser (Lasser-Coulter). Cada curva corresponde al porcentaje de grano (\% grano) de una muestra. Los campos granulométricos han sido divididos por diámetro: arcilla $(<4 \mu \mathrm{m})$, limo $(4-64 \mu \mathrm{m})$, >arena fina $(64-250 \mu \mathrm{m})$. Los histogramas corresponden a la media de cada perfil (Figura 4 , Tabla 2$)$. 
Tabla 3. Estimación modal mineralógica por microscopía de luz transmitida de los contenidos de fragmentos y minerales (ferromagnesianos) de roca encajonante, minerales de ganga (cuarzo, feldespato y calcita), opacos (óxidos y sulfuros) y secundarios (arcillas); y estimación modal mineralógica por microscopía de luz reflejada de los minerales opacos (después de Maldonado-Villanueva, 2008). Abreviaciones: líticos (L); máficos (maf); cuarzo (Qz); feldespatos (fel); calcita (cal); pirita (Py); ilmenita (Ilm); hematita (Hem); Calcopirita (Cp); Arsenopirita (Apy); Galena (Gn); Titanomagnetita (Tm ); Magnetita (Mg); Freibergita (Fr); Oro rico en plata (electrum) $(\mathrm{Au}) ;$ Goethita $=(\mathrm{Gth}) ; \mathrm{Po}=$ Pirrotita; $\mathrm{A}=$ aguilerita; $\mathrm{Cv}=$ covelita.

\begin{tabular}{|c|c|c|c|c|c|c|c|c|c|c|c|c|}
\hline \multicolumn{13}{|c|}{ TLALPUJAHUA } \\
\hline \multirow{3}{*}{ Muestra } & \multicolumn{7}{|c|}{ Petrografía } & \multirow[t]{3}{*}{ Mineragrafía } & \multicolumn{4}{|c|}{ Granulometría $(\mu \mathrm{m})$} \\
\hline & \multicolumn{2}{|c|}{ encajonante } & \multicolumn{4}{|c|}{ depósito mineral } & \multirow{2}{*}{$\frac{\text { alteración }}{\text { limo-arcilla }}$} & & \multirow[b]{2}{*}{$<4$} & \multirow[b]{2}{*}{$>4-64$} & \multirow[b]{2}{*}{$>64-250$} & \multirow[b]{2}{*}{$>250$} \\
\hline & $L$ & maf & $Q z$ & fel & cal & opaco & & & & & & \\
\hline EI-H1 & 80 & 5 & 2 & 3 & - & 1 & 9 & & - & - & - & - \\
\hline EI-H2 & 87 & 3 & 2 & 3 & - & 1 & 4 & & - & - & - & - \\
\hline EI-H3 & 86 & 4 & 3 & 6 & - & 1 & - & & - & - & - & - \\
\hline EII-H1* & 4 & 1 & 53 & 8 & 8 & 1 & 25 & & 2.1 & 26.9 & 67.9 & 3.2 \\
\hline EII-H2 & 5 & 1 & 68 & 8 & 8 & 2 & 8 & & 7.4 & 74.6 & 18.0 & - \\
\hline EII-H3* & 5 & 2 & 43 & 29 & 8 & 2 & 11 & & 10.2 & 89.2 & 0.6 & - \\
\hline EIII-H1* & 4 & 5 & 49 & 12 & 12 & 2 & 16 & Py, Gth, & 15.2 & 84.8 & - & - \\
\hline EIII-H2* & 20 & 4 & 50 & 5 & 12 & 1 & 8 & Py, Hem, Gt & 7.2 & 45.4 & 47.4 & - \\
\hline EIII-H3* & 8 & 7 & 63 & 4 & 12 & 2 & 4 & Py, Gn, Hem & 3.0 & 34.8 & 62.3 & - \\
\hline EIII-H4* & 4 & 2 & 3 & 2 & 8 & 1 & 80 & & 9.0 & 71.0 & 19.0 & 1.0 \\
\hline EIII-H5* & 8 & - & 7 & 1 & 8 & 1 & 75 & Ilm, Tm, Gn, Hem, Gth & 3.0 & 73.0 & 22.0 & 2.0 \\
\hline EIII-H6* & 4 & - & 7 & 4 & 8 & 1 & 76 & Ilm, Tm, Mg, Py, Gn, Gth & 12.5 & 87.4 & - & - \\
\hline EIII-H7* & - & - & - & - & - & - & - & & - & - & - & - \\
\hline EIV-H1 & 22 & 2 & 43 & 12 & 10 & 2 & 9 & & - & - & - & - \\
\hline EIV-H2* & 25 & 3 & 31 & 15 & 12 & 2 & 12 & Ilm, Mg, Py, Hem & 10.7 & 88.7 & 0.6 & - \\
\hline EIV-H3 & 21 & 2 & 52 & 3 & 12 & 2 & 8 & & 0.0 & 0.0 & 0.0 & - \\
\hline EIX-H1* & 4 & 2 & 36 & 9 & 34 & 4 & 11 & & 10.4 & 89.0 & 0.6 & - \\
\hline $\mathrm{EIX}-\mathrm{H} 2^{*}$ & 5 & 2 & 32 & 7 & 27 & 4 & 23 & & 8.0 & 77.4 & 14.6 & - \\
\hline EIX-H3* & 14 & 4 & 36 & 11 & 20 & 3 & 12 & Hem, Gth & 11.3 & 88.1 & 0.6 & - \\
\hline EIX-H4* & 15 & 2 & 34 & 10 & 8 & 4 & 27 & Py, Cp, Mg, Hem, Gth & 13.8 & 85.9 & 0.4 & - \\
\hline EIX-H5* & 10 & 5 & 61 & 5 & 12 & 5 & 2 & & 1.2 & 9.5 & 25.4 & 63.9 \\
\hline EX-H1 & 7 & 2 & 50 & 8 & 18 & 4 & 11 & & 10.0 & 69.7 & 20.3 & - \\
\hline $\mathrm{EX}-\mathrm{H} 2^{*}$ & 12 & 4 & 57 & 4 & 12 & 5 & 6 & Py, Cp, Mg, Hem, Gth & 5.5 & 62.6 & 31.9 & - \\
\hline EX-H4 ${ }^{*}$ & 6 & 3 & 59 & 5 & 16 & 4 & 7 & Cp, Hem, Gth & 6.4 & 93.1 & 0.5 & - \\
\hline EXI-H1* & 5 & 4 & 63 & 3 & 16 & 3 & 6 & & 4.8 & 76.1 & 19.0 & - \\
\hline EXI-H2* & 4 & 2 & 59 & 5 & 16 & 4 & 10 & & 8.5 & 77.3 & 14.2 & - \\
\hline EXI-H3* & 8 & 1 & 59 & 8 & 16 & 5 & 3 & & 2.3 & 62.2 & 35.4 & - \\
\hline EXI-H4 ${ }^{*}$ & 7 & 1 & 56 & 7 & 16 & 4 & 9 & & 7.6 & 64.3 & 28.1 & - \\
\hline EXI-H5 ${ }^{*}$ & 27 & 1 & 49 & 3 & 16 & 2 & 2 & & 0.5 & 5.9 & 20.7 & 72.9 \\
\hline EXI-H6* & 87 & - & 3 & - & 8 & - & 2 & & 1.1 & 9.6 & 25.4 & 63.9 \\
\hline EXII-H1* & 8 & - & 68 & 3 & 5 & 3 & 13 & & 12.4 & 87.6 & - & - \\
\hline EXII-H2 & 17 & 5 & 64 & 7 & 3 & 2 & 2 & & 1.1 & 10.4 & 88.5 & - \\
\hline EXII-H3* & 4 & 1 & 73 & 7 & 12 & 2 & 1 & & 0.1 & 1.6 & 51.9 & 46.4 \\
\hline EXII-H4* & 13 & 4 & 58 & 9 & 12 & 2 & 2 & & 1.1 & 8.4 & 23.8 & 66.6 \\
\hline EXIII-H1* & - & - & - & - & - & - & - & & 21.0 & 79.0 & - & - \\
\hline EXIII-H2 & 11 & 2 & 42 & 12 & 20 & 4 & 9 & & 8.0 & 43.5 & 48.5 & - \\
\hline EXIII-H3 & 12 & 3 & 57 & 10 & 2 & 4 & 12 & & 11.1 & 61.1 & 27.8 & - \\
\hline EXIII-H4* & 10 & 3 & 62 & 8 & 2 & 3 & 12 & & 11.4 & 60.8 & 27.8 & - \\
\hline
\end{tabular}

\section{Petrografía y texturas}

Las muestras de jales en sección delgada exhiben una textura de apariencia de "pseudo-arenisca" de grano fino e inmadura, con clastos angulosos, característicos del efecto de la molienda (Figuras 6a y 6b) y una gran cantidad de matriz limo-arcillosa $(>64-150 \mu \mathrm{m})$ de color café, ocre a grisáceo. Sin embargo, la proporción de arcillas no es evidente, en cuanto es difícil establecer una clara diferencia con la micrita o lodo calcáreo. La proporción modal de los componentes se presenta en la Tabla 3 y en la Figura 7. Con ligeras variaciones, los porcentajes medios de los clastos de jales del DIMITO indican un predominio del cuarzo entre 53 y $68 \%$, seguido de líticos (7-20\%) y de calcita con un promedio de $\sim 12 \%$ y minerales opacos entre 1 y $3 \%$, con un evidente predominio de óxidos sobre los sulfuros. En cuanto a los líticos, éstos consisten de una composición andesítica y calcárea; en Tlalpujahua corresponden a $>15$ $\%$, mientras que en El Oro es $<7.5 \%$ del volumen total. Los feldespatos están siempre presentes en todos depósitos de jales, con porcentajes del 7-9 \%. En todas las muestras se presentan silicatos ferromagnesianos (anfíbol, piroxeno, clorita) con un porcentaje entre 2 y $3 \%$. 
Tabla 3 (continuación). Estimación modal mineralógica por microscopía de luz transmitida de los contenidos de fragmentos y minerales (ferromagnesianos) de roca encajonante, minerales de ganga (cuarzo, feldespato y calcita), opacos (óxidos y sulfuros) y secundarios (arcillas); y estimación modal mineralógica por microscopía de luz reflejada de los minerales opacos (después de Maldonado-Villanueva, 2008). Abreviaciones: líticos (L); máficos (maf); cuarzo (Qz); feldespatos (fel); calcita (cal); pirita (Py); ilmenita (Ilm); hematita (Hem); Calcopirita (Cp); Arsenopirita (Apy); Galena (Gn); Titanomagnetita (Tm ); Magnetita (Mg); Freibergita (Fr); Oro rico en plata (electrum) $(\mathrm{Au}) ;$ Goethita $=(\mathrm{Gth}) ; \mathrm{Po}=$ Pirrotita; $\mathrm{A}=$ aguilerita; $\mathrm{Cv}=$ covelita.

\begin{tabular}{|c|c|c|c|c|c|c|c|c|c|c|c|c|}
\hline \multicolumn{13}{|c|}{ EL ORO } \\
\hline \multirow{3}{*}{ muestra } & \multicolumn{7}{|c|}{ Petrografía } & \multirow[t]{3}{*}{ Mineragrafía } & \multicolumn{4}{|c|}{ Granulometría $(\mu \mathrm{m})$} \\
\hline & \multicolumn{2}{|c|}{ encajonante } & \multicolumn{4}{|c|}{ depósito mineral } & \multirow{2}{*}{$\begin{array}{c}\text { alteración } \\
\text { limo-arcilla }\end{array}$} & & \multirow[b]{2}{*}{$<4$} & \multirow[b]{2}{*}{$>4-64$} & \multirow[b]{2}{*}{$>64-250$} & \multirow[b]{2}{*}{$>250$} \\
\hline & $L$ & maf & $Q z$ & $f e l$ & cal & opaco & & & & & & \\
\hline $\mathrm{EV}-\mathrm{H} 1^{*}$ & 17 & 1 & 55 & 7 & 12 & 1 & 7 & & 5.7 & 86.1 & 8.3 & - \\
\hline $\mathrm{EV}-\mathrm{H} 2^{*}$ & 3 & 6 & 54 & 15 & 8 & 3 & 11 & Py, Ilm, Hem, Gth & 10.3 & 75.3 & 14.4 & - \\
\hline $\mathrm{EV}-\mathrm{H} 3 \mathrm{~A}^{*}$ & 3 & 2 & 32 & 3 & 12 & 3 & 45 & Py, Ilm, Hem, Gth & 5.8 & 71.4 & 22.8 & - \\
\hline EV-H3B & 2 & 2 & 49 & 17 & 12 & 3 & 15 & & 13.7 & 78.2 & 8.1 & - \\
\hline EV-H3C & 3 & 1 & 63 & 5 & 12 & 2 & 14 & & 13.0 & 82.7 & 4.3 & - \\
\hline $\mathrm{EV}-\mathrm{H} 4^{*}$ & 3 & 3 & 57 & 15 & 12 & 3 & 7 & Py, Gn, Ilm, Gth & 6.4 & 64.4 & 29.1 & - \\
\hline $\mathrm{EV}-\mathrm{H} 5^{*}$ & 5 & 1 & 48 & 16 & 12 & 3 & 15 & Py, Po, Mg, Gn, Hem, Gth & 14.6 & 79.5 & 6.0 & - \\
\hline EV-H6* & 3 & 1 & 31 & 9 & 4 & 4 & 48 & Po, Gn, Gth & 0.0 & 0.0 & - & - \\
\hline EVII-H1* & 5 & 1 & 52 & 12 & 12 & 3 & 15 & Py, Hem, Gth & 16.8 & 83.2 & - & - \\
\hline EVII-H2 & 5 & - & 49 & 13 & 12 & 7 & 14 & & 13.4 & 86.6 & - & - \\
\hline EVII-H3* & 4 & 3 & 48 & 11 & 12 & 3 & 19 & Py, Cp, Apy, Au, Fr, A, Cv, Gth & 17.6 & 82.4 & - & - \\
\hline EVII-H4 $4^{*}$ & 8 & 4 & 48 & 13 & 5 & 4 & 18 & Py, Cp, A, Fr, Hem, Gth & 16.7 & 83.2 & - & - \\
\hline EVII-H5* & 7 & - & 56 & 12 & 4 & 2 & 19 & Ilm, Hem, Gth & 17.6 & 82.4 & - & - \\
\hline EVII-H6* & 6 & - & 60 & 12 & 4 & 2 & 16 & Ilm, Gn, Hem & 14.7 & 73.8 & 11.5 & - \\
\hline EVII-H7* & 5 & - & 50 & 12 & 4 & 2 & 27 & Ilm, Gn, Hem, Gth & 19.0 & 80.6 & 0.3 & - \\
\hline ME07m* & 6 & 1 & 60 & 12 & 12 & 2 & 7 & & - & - & - & - \\
\hline ME07c $c^{*}$ & 7 & 1 & 60 & 12 & 12 & 2 & 6 & & - & - & - & - \\
\hline EVIII-H1* & 8 & 2 & 48 & 13 & 12 & 3 & 14 & & 12.9 & 87.1 & - & - \\
\hline EVIII-H2* & 1 & - & 43 & 6 & 2 & 3 & 45 & & 13.2 & 86.8 & - & - \\
\hline EVIII-H3* & 8 & 1 & 55 & 12 & 12 & 2 & 10 & & 9.1 & 77.1 & 13.8 & - \\
\hline EVIII-H4* & 1 & - & 31 & 3 & 45 & 5 & 15 & & 14.1 & 85.5 & 0.4 & - \\
\hline EXIV-H1 & 3 & 1 & 58 & 6 & 12 & 3 & 17 & & 16.0 & 84.0 & - & - \\
\hline EXIV-H2* & 3 & 2 & 54 & 5 & 12 & 4 & 20 & & 19.1 & 80.7 & 0.3 & - \\
\hline EXIV-H3 & 2 & 2 & 24 & 3 & 20 & 3 & 46 & & 16.5 & 83.2 & 0.3 & - \\
\hline EXIV-H4 & 4 & 1 & 43 & 3 & 12 & 2 & 35 & & 19.7 & 80.3 & - & - \\
\hline EXIV-H5 & 10 & 1 & 34 & 1 & 12 & 4 & 38 & & 11.1 & 77.0 & 12.0 & - \\
\hline EXIV-H6 & 3 & - & 63 & 4 & 12 & 5 & 13 & & 11.9 & 66.3 & 21.9 & - \\
\hline EXIV-H7 & 10 & 1 & 25 & 2 & 44 & 3 & 15 & & 13.6 & 74.4 & 11.9 & - \\
\hline EXIV-H8* & 9 & - & 59 & 2 & 12 & 3 & 15 & & 14.1 & 82.6 & 3.3 & - \\
\hline
\end{tabular}

\section{Mineragrafía y texturas de los minerales opacos de los jales DIMITO}

Una vez separada la fracción de $\leq 1-5 \%$ de los minerales metálicos, se observa que el tamaño de los minerales opacos es muy heterogéneo, puede variar desde $0.5 \mathrm{~mm}$ hasta $\sim 4 \mu \mathrm{m}$, sin embargo, la dimensión media está entre 30-350 $\mu \mathrm{m}$ (Figura 6c). Es notable la ocurrencia de pirita ( \pm ilmenita), con tamaños entre 50 a $200 \mu \mathrm{m}$, ya sea como fragmentos dispersos o como inclusiones en minerales transparentes como el cuarzo (Figura 6d). En orden de abundancia se identificaron tres grandes grupos de minerales opacos: i) óxidos $\geq 1.5 \%$, ilmenita $\left(\mathrm{FeTiO}_{3}\right)$, magnetita $\left(\mathrm{Fe}_{3} \mathrm{O}_{4}\right)$; hematita $\left(\mathrm{Fe}_{2} \mathrm{O}_{3}\right)$, goethita $[\mathrm{FeO}(\mathrm{OH})]$, ii) sulfuros entre 0.5 y $1.5 \%$, pirita $\left(\mathrm{FeS}_{2}\right)$, calcopirita $\left(\mathrm{FeCuS}_{2}\right)$, galena $(\mathrm{PbS})$, pirrotita $\left[\mathrm{Fe}_{(1-\mathrm{x})} \mathrm{S}_{(0-0.17)}\right]$, argentita $\left(\mathrm{Ag}_{2} \mathrm{~S}\right)$, arsenopirita (FeAsS), covelita $\left(\mathrm{Cu}_{5} \mathrm{FeS}_{4}\right)$ y, iii) sulfusales auro-argentíferas complejas $<1 \%$, como aguilerita-freibergita $\left(\mathbb{A g}_{6} \mathrm{Cu}_{4} \mathrm{Fe}_{2} \mathrm{Sb}_{4} \mathrm{~S}_{13}\right)$, tennantita $\left.(\mathrm{Cu}, \mathrm{Fe})_{12} \mathrm{As}_{4} \mathrm{~S}_{13}\right)$ y excepcionalmente metales nativos como Au y Ag. Las sulfosales son de tamaño variable y pueden alcanzar las $100 \mu \mathrm{m}$. En general se muestran bien preservadas y con frecuencia exhiben texturas internas de exsolución o intercrecimientos de otras fases, como calcopirita-aguilerita y freibergita (Figura 6e). Por el contrario, la pirita muestra un intenso reemplazamiento por alteración asociado con el crecimiento de hidróxidos goethita-limonita y hematita (Figura 6f). La pirita y la ilmenita con diámetros $<50 \mu \mathrm{m}$, los cuales se encuentran contenidos como inclusiones en el cuarzo se observan prácticamente inalterados (Figura 6d). La diversidad de los minerales opacos primarios se correlaciona bien con la paragénesis reportada para el depósito de vetas epitermales del DIMITO (De la Teja-Segura et al., 1999), mientras que, los minerales secundarios sólo se identificaron bajo forma de bordes o intercrecimentos lamelares de hidróxidos de Fe (e.g. goethita, hematita; Figuras 6c y 6f). Sin embargo, algunos hidróxidos también podrían ser de tipo primario tardío en el sistema hidrotermal del DIMITO (Albinson et al., 2001).

\section{Difracción de rayos $\mathrm{X}$ y Microscopía electrónica de barrido}

En la Figura 8 se presentan dos difractogramas representativos de los jales del DIMITO, en donde se observan algunas variedades de sílice como el cuarzo $\left(\mathrm{SiO}_{2}\right)$ y cristobalita $\left(\alpha \mathrm{SiO}_{2}\right)$, esmectita $\left(\mathrm{Al}_{2} \mathrm{O}_{5} 4 \mathrm{SiO}_{2} \mathrm{xH}_{2} \mathrm{O}\right)$, caolinita $\left(\mathrm{Al}_{2} \mathrm{Si}_{2} \mathrm{O}_{5} 4 \mathrm{SiO}_{2} \mathrm{x}(\mathrm{OH})_{4}\right)$, albita $\left(\mathrm{NaAlSi}_{3} \mathrm{O}_{6}\right)$, calcita $\left(\mathrm{CaCO}_{3}\right)$, magnetita $\left(\mathrm{Fe}_{3} \mathrm{O}_{4}\right)$, hematita $\left(\mathrm{Fe}_{2} \mathrm{O}_{3}\right)$, goethita $(\mathrm{FeO}(\mathrm{OH}))$. Estas fases han sido reportadas comúnmente 
como fases secundarias (Jambor, 1994) y podrían estar contenidas en la matriz en dimensiones sub-microscópicas y/o en formas de alteración y subordinadas a fases primarias. Con base en el análisis de imágenes generadas por electrones retro-dispersados (BSE; Figuras 8 c y $8 d$ ) y de espectroscopía semicuantitativa de dispersión de energía (EDS, Figura 9), se llevó a cabo la identificación detallada de la composición y estado de oxidación de las fases minerales. Cuando la pirita supera una dimensión $>80 \mu \mathrm{m}$, se observa que su estructura interna ha sido ampliamente descompuesta, mostrando una textura esqueletal asociada con el desarrollo de ferrhidrita en forma de lamelas que pueden variar desde 1-10 $\mu \mathrm{m}$ (Figuras 6f y 8c). En contraste, los minerales metálicos de ilmenita y pirita de dimensiones hasta de 100 $\mu \mathrm{m}$, se observan encapsulados en cristales de cuarzo, en los cuales no muestran algún tipo de alteración (Figuras $6 \mathrm{~d}$ y $8 \mathrm{~d}$ ). Las sulfosales con dimensiones $>200 \mu \mathrm{m}$ muestran una zonación compleja (Figura $6 e$ ). Se determinó un borde de hierro muy delgado $2-3 \mu \mathrm{m}$, seguido por una zona de calcopirita y en el nucleo sulfosales auro-argentíferas aguilerita-freibergita (Figura 9).

\section{Geoquímica de los jales del DIMITO}

En la Tabla 4 se presentan las concentraciones de elementos mayores de 48 muestras de los jales del DIMITO. En orden de abundancia, se puede observar que el silicio es el elemento dominante, con un rango de valores entre 56 y $92 \%$ (en peso), seguido por el aluminio que varía de 5 a $13 \%$, el hierro de 3 a $5 \%$, el calcio de 2.5 a $5 \%$ y el potasio de 1 a $2 \%$. En general, las concentraciones de los elementos mayores muestran una estrecha correlación con la mineralogía modal y en particular con los porcentajes del cuarzo, las arcillas y los líticos (Tabla 3, Figura 7). En la Figura 10, se presentan una serie de diagramas binarios que muestran la variación de las concentraciones del $\mathrm{Al}_{2} \mathrm{O}_{3}, \mathrm{CaO}$ y $\mathrm{Fe}_{\text {Total }}$ en relación con las concentraciones del $\mathrm{SiO}_{2}$ y los valores del $\mathrm{pH}$. Los datos fueron agrupados por estación de muestreo y a su vez fueron separados en subgrupos, en relación con su posición estratigráfica: basal, intermedia o cima. Para su correlación, también se han graficado algunos datos promedio de otros distritos mineros del país: Guanajuato (Ramos-Arroyo et al., 2004), Taxco (Talavera et al., 2005; Armienta et al. 2003), Zimapán (Armienta y Segovia, 2008) y Santa Bárbara (Martín-Romero et al., 2008). En principio es interesante notar que, cuando los valores $\mathrm{de}^{\mathrm{SiO}_{2}}$ son $>65 \%$, se observa una relativa tendencia lineal con el aluminio, el hierro y el calcio. Esta tendencia sugiere una estrecha relación entre estos elementos con el incremento del cuarzo y feldespatos, por lo tanto, con los procesos hipogénicos (e.g. magmático/hidrotermal) del depósito mineral. Sin embargo, cuando los valores de $\mathrm{SiO}_{2}$ son $<65 \%$, el $\mathrm{CaO}$ y Fe $\mathrm{Fotal}_{\text {Tol }}$ muestran una
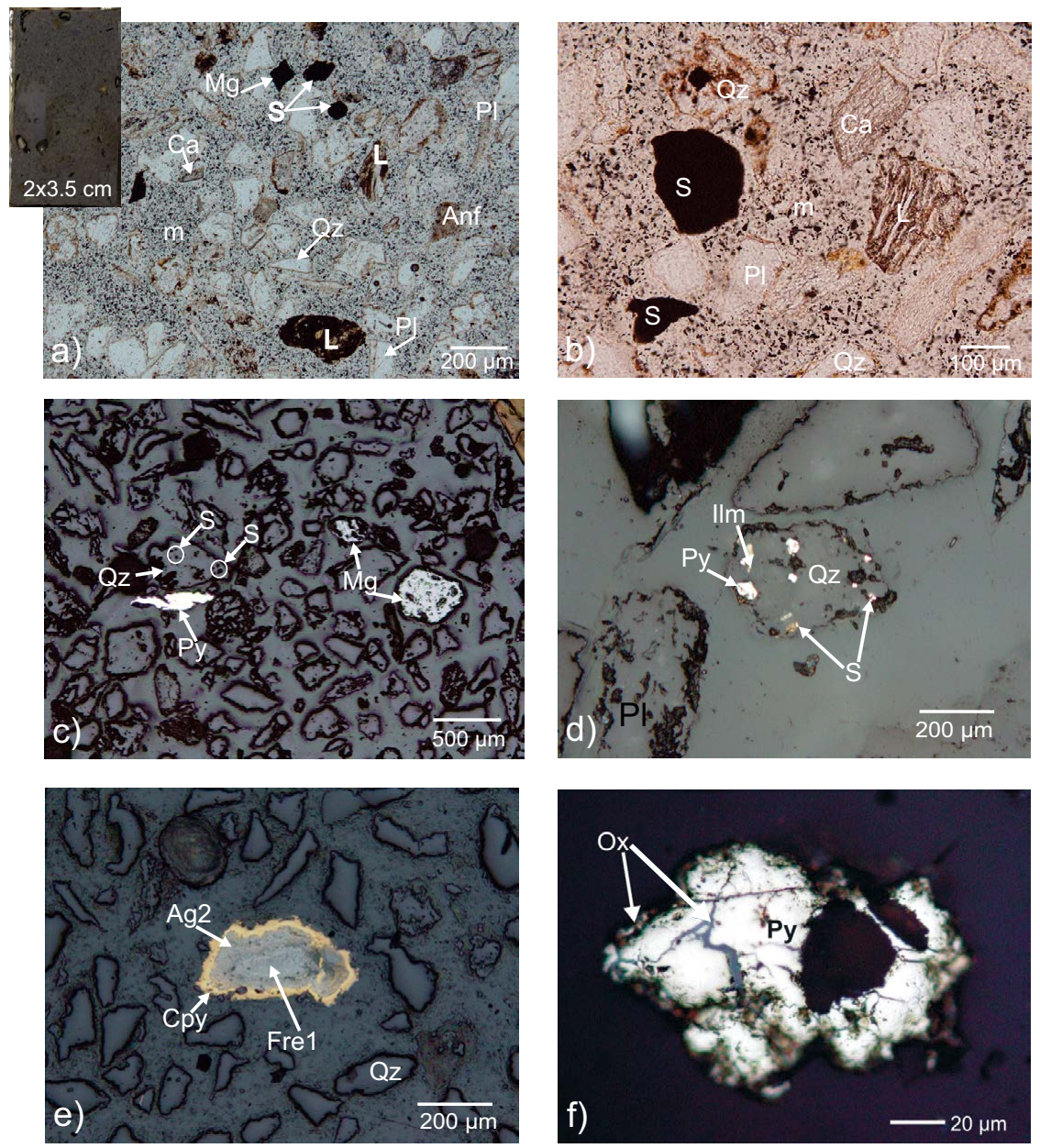

Figura 6. Fotomicrografías ópticas de los jales del DIMITO. a y b) Luz transmitida, EVII-H2, Tiro México. Notar en el extremo superior izquierdo, la foto de la briqueta de la muestra. c) Luz reflejada de separado de minerales opacos, EVII-H2. d) EVII-H3, inclusión de pirita en fragmento de cuarzo. e) Luz reflejada de sulfosal compleja de Ag-Sb-Au. f) Luz reflejada de clasto de pirita $>100 \mu \mathrm{m}$ con textura lamelar y bordes de hematita-goethita. Abreviaciones: calcita (Ca); magnetita $(\mathrm{Mg})$; sulfuros (S); plagioclasa (Pl); Anfíbol (Anf); líticos (L); matriz (m); cuarzo (Qz); pirita (Py); ilmenita (Ilm); calcopirita (Cpy); freibergita (Fre1); aguilerita (Ag2); óxidos (Ox). 


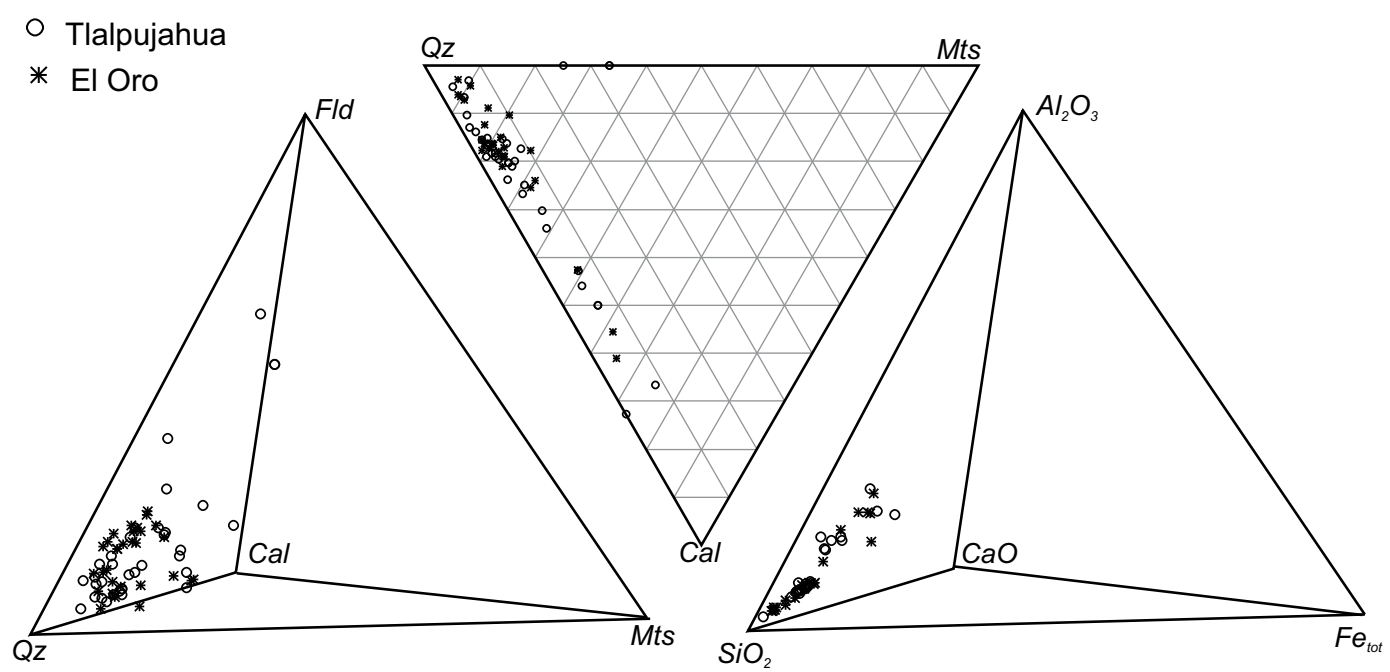

Figura 7. Diagramas tetraedrales y uno triangular que muestran la correlación geoquímica de los minerales esenciales (cuarzo, calcita, feldespatos, opacos; Tabla 3) y los elementos mayores ( $\mathrm{CaO}, \mathrm{SiO}_{2}, \mathrm{Al}_{2} \mathrm{O}_{3}, \mathrm{Fe}_{\text {Total }}$ Tabla 4) de los jales del DIMITO. Abreviaciones: cuarzo (Qz), feldespatos (Fld), minerales opacos (Mts), calcita (Cal).
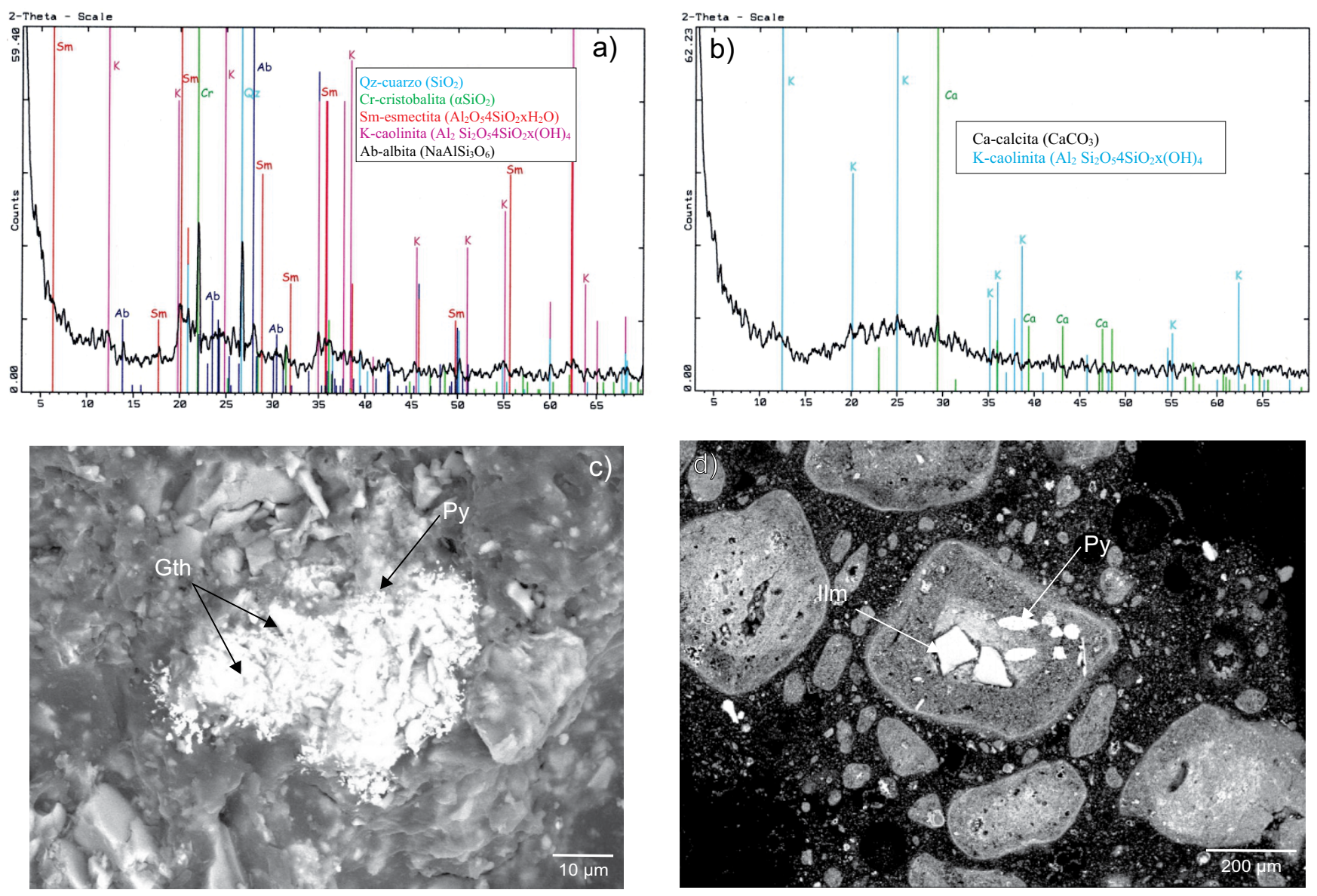

Figura 8. a y b) Difractogramas de polvos de jales y costras blanquecinas de los jales DIMITO. Variedades de sílice como el cuarzo $\left(\mathrm{SiO}_{2}\right)$ y cristobalita $\left(\alpha \mathrm{SiO}_{2}\right)$, esmectita $\left(\mathrm{Al}_{2} \mathrm{O}_{5} 4 \mathrm{SiO}_{2} \mathrm{xH}_{2} \mathrm{O}\right)$, caolinita $\left(\mathrm{Al}_{2} \mathrm{Si}_{2} \mathrm{O}_{5} 4 \mathrm{SiO}_{2} \mathrm{x}(\mathrm{OH})_{4}\right.$, albita $\left(\mathrm{NaAlSi}_{3} \mathrm{O}_{6}\right)$, calcita $\left(\mathrm{CaCO}_{3}\right)$, magnetita $\left(\mathrm{Fe}_{3} \mathrm{O}_{4}\right)$; hematita $\left(\mathrm{Fe}_{2} \mathrm{O}_{3}\right)$, goethita $[\mathrm{FeO}(\mathrm{OH})]$. c) Imágen de electrones retro-dispersados de pirita $(\mathrm{Py})$ con textura esponjosa asociada con el desarrollo de goethita (Gth). d) Imágen de electrones retro-dispersados de fragmentos de pirita (Py) e ilmenita (Ilm) inalterados y encapsulados en un fragmento de cuarzo. 

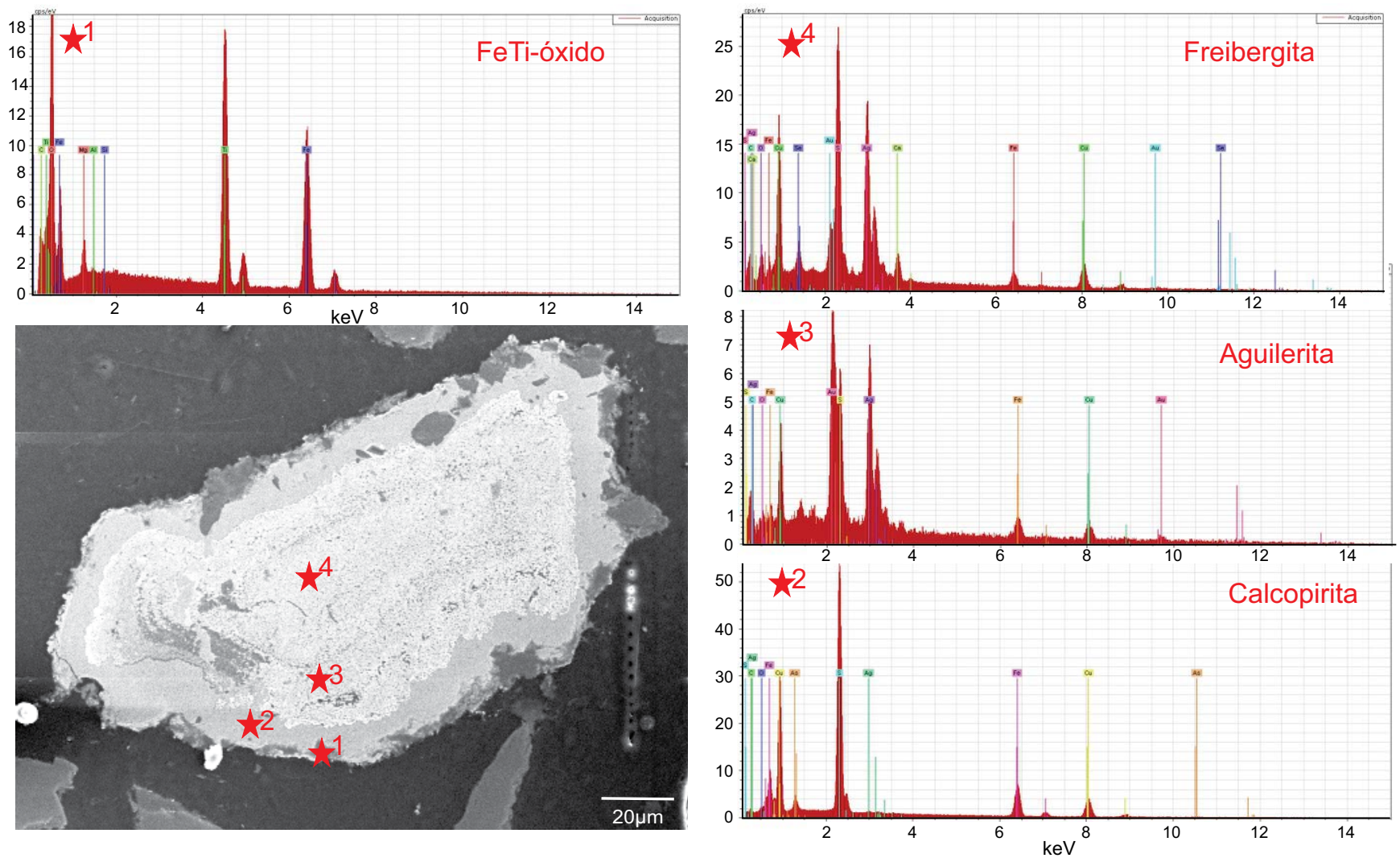

Figura 9. Imagen de electrones retro-dispersados y puntos de microanálisis semicuantitativos de Dispersión de Energía de rayos X. Notar la determinación de las fases del borde al nucleo: 1) óxido de hierro-titanio (ilmenita), 2) calcopirita, 3) aguilerita y 4) freibergita.

relativa dispersión, probablemente relacionada con la presencia de los carbonatos para el calcio y/o de material arcilloso para el hierro. $\mathrm{La}$ influencia de los carbonatos en las variaciones de $\mathrm{CaO}$ y $\mathrm{Fe}_{\text {Total }}$ es aún mas evidente en los diagramas versus el $\mathrm{pH}$, donde sus mayores concentraciones, en particular las del calcio, se agrupan con los valores de $\mathrm{pH} \geq 7.5$. Por el contrario, estos elementos muestran un decremento exponencial en relación con los valores más bajos del $\mathrm{pH}<7$ a 5 , en coincidencia con las muestras de algunos horizontes basales de los perfiles III, XI de Tlalpujahua y VII y VIII de El Oro. Por su parte, el aluminio muestra una tendencia opuesta a la del calcio, el cual tiende a incrementarse en relación con la disminución del $\mathrm{pH}$, sugiriendo una baja participación como potencial de neutralización de las arcillas y feldespatos.

En la Tabla 5 se presentan las concentraciones de 43 elementos traza determinados en 48 muestras de los jales del DIMITO, así como de dos muestras de terreros, en los que se analizaron los contenidos de Au y Ag. Se observa que las concentraciones de los lantánidos o Tierras Raras no muestran anomalías relevantes respecto a los valores estandard de un suelo (Markert, 1987). En la Figura 11 se presentan una serie de diagramas binarios que muestran la variación de las concentraciones de los EPT: $\mathrm{Cu}, \mathrm{As}, \mathrm{Sb}, \mathrm{Cd}$ y de los EPE: Ag, Au, $\mathrm{Pb}, \mathrm{Zn}$ en relación con las concentraciones del $\mathrm{SiO}_{2}$ y los valores del $\mathrm{pH}$. Para su comparación y análisis con los elementos mayores, las muestras han sido agrupadas como en la Figura 10, también se han incorporado los límites máximos permisibles de toxicidad para suelos (LMP) reportados por la Organización Mundial de Salud (WHO, 2015). Los jales del DIMITO muestran una tendencia geoquímica de EPT y EPE relativamente homogénea. Sin embargo, los horizontes basales de algunos depósitos de jales de El Oro (V, VII, VIII, XIV,
Me07) y de Tlalpujahua (IX, XII), muestran mayores concentraciones de EPE y de Sb, Cd. Los EPT presentan concentraciones que varían de: As (25.2-40.5 g/ton), Cd (0.54-0.74 g/ton), Sb (43.9-72.2 g/ton), $\mathrm{Cu}$ (40.3-44.2 g/ton), $\mathrm{Pb}$ (53.3-145.2 g/ton) y Zn (155.9-354.5 g/ton). Aunque, aparentemente, las concentraciones de los EPT se encontrarían debajo de los LMP de la norma mexicana (SEMARNAT, 2011, NOM157-2009), se observa que, de acuerdo a los LMP establecidos por la OMS (WHO, 2015), la concentración del Sb supera ampliamente el límite de alto riesgo (50 mg/kg). Del mismo modo, una docena de muestras con distribción aleatoria, muestran concentraciones de As, $\mathrm{Zn}$ y $\mathrm{Pb}$ que se encuentran ligeramente arriba de LMP de bajo riesgo (50 mg/kg, $250 \mathrm{mg} / \mathrm{kg}$ y $200 \mathrm{mg} / \mathrm{kg}$, respectivamente), mientras que las concentraciones de $\mathrm{Cu}$ y $\mathrm{Cd}$, se encuentran por debajo de ambas normas. Por otro lado, en la Figura 11, se observa una relativa tendencia lineal positiva entre el incremento de algunos valores de EPT (e.g. Sb, As) y EPE (e.g. Ag, Pb, Zn) con las concentraciones del $\mathrm{SiO}_{2}>65 \%$ y ligeramente con los valores de $\mathrm{pH} \geq 7.5$. Esta tendencia sugiere una estrecha relación entre estos elementos, bajo forma de sulfuros y sulfosales remanentes en el jal, así como que estarían asociados principalmente con el cuarzo, como estarían ligeramente subordinadas con un incremento de la matriz calcáreo-carbonosa. Por su parte, las concentraciones de los EPE para este tipo de depósito mineral (e.g. Au, Ag, $\mathrm{Pb}, \mathrm{Zn}$ ), ya sea en la mayoría de los jales como en las dos muestras de terreros ( $\mathrm{Te} 01, \mathrm{Te} 02)$, muestran valores que representarían leyes mineras potencialmente remunerables con valores medios de Au (1.2-1.61 g/ton), Ag (28.1-46.8 g/ton), Pb (53.3$145.2 \mathrm{~g} / \mathrm{ton})$ y Zn (155.9-354.5 g/ton). Estas leyes coinciden con los ensayes reportados por otros autores (Aguilar-Contreras, 1971; Candente, 2014). Es importante señalar que las concentraciones de 
Tabla 4. Resultados geoquímicos de 48 muestras de jales del DIMITO. Los elementos mayores (\%wt) fueron obtenidos por fluorescencia de rayos X (FRX).

\begin{tabular}{|c|c|c|c|c|c|c|c|c|c|c|c|c|c|}
\hline & Muestra & $\mathrm{SiO}_{2}$ & $\mathrm{TiO}_{2}$ & $\mathrm{Al}_{2} \mathrm{O}_{3}$ & $\mathrm{FeO}_{\text {total }}$ & $\mathrm{MnO}$ & $\mathrm{MgO}$ & $\mathrm{CaO}$ & $\mathrm{Na}_{2} \mathrm{O}$ & $\mathrm{K}_{2} \mathrm{O}$ & $\mathbf{P}_{2} \mathbf{O}_{5}$ & Suma & $P \times C$ \\
\hline \multirow{48}{*}{ 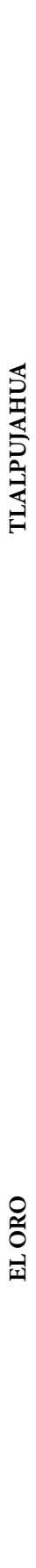 } & EII-H1 & 69.88 & 0.31 & 6.19 & 3.42 & 0.08 & 0.68 & 3.81 & 0.26 & 1.86 & 0.19 & 86.67 & 14.14 \\
\hline & EII-H3 & 75.85 & 0.25 & 6.05 & 3.31 & 0.08 & 0.68 & 5.59 & 0.13 & 2.00 & 0.11 & 94.04 & 5.85 \\
\hline & EIII-H1 & 79.72 & 0.23 & 5.01 & 2.54 & 0.07 & 0.57 & 3.51 & 0.14 & 1.67 & 0.09 & 93.53 & 6.09 \\
\hline & EIII-H2 & 75.83 & 0.28 & 6.91 & 3.13 & 0.13 & 0.78 & 5.26 & 0.18 & 1.97 & 0.09 & 94.57 & 6.53 \\
\hline & EIII-H3 & 79.19 & 0.27 & 5.75 & 2.74 & 0.07 & 0.59 & 4.01 & 0.16 & 1.65 & 0.08 & 94.49 & 5.28 \\
\hline & EIII-H4 & 56.62 & 0.90 & 22.27 & 5.97 & 0.02 & 1.05 & 1.72 & 0.74 & 1.06 & 0.03 & 90.37 & 9.05 \\
\hline & EIII-H5 & 56.78 & 0.72 & 18.37 & 11.54 & 0.03 & 1.66 & 1.76 & 1.11 & 0.27 & 0.04 & 92.26 & 7.43 \\
\hline & EIII-H6 & 58.22 & 0.74 & 18.75 & 8.65 & 0.02 & 1.35 & 1.85 & 1.27 & 0.48 & 0.06 & 91.40 & 8.46 \\
\hline & EIII-H7 & 69.95 & 0.44 & 14.56 & 4.90 & 0.02 & 1.41 & 0.68 & 0.14 & 2.39 & 0.07 & 94.55 & 5.06 \\
\hline & EIV-H2 & 73.27 & 0.35 & 7.27 & 3.49 & 0.08 & 0.93 & 4.64 & 0.26 & 1.86 & 0.12 & 92.26 & 7.05 \\
\hline & EIX-H1 & 78.40 & 0.24 & 6.09 & 2.85 & 0.07 & 0.69 & 3.70 & 0.14 & 1.96 & 0.11 & 94.26 & 6.25 \\
\hline & EIX-H2 & 79.27 & 0.23 & 5.95 & 2.82 & 0.07 & 0.70 & 3.78 & 0.10 & 1.92 & 0.10 & 94.95 & 4.99 \\
\hline & EIX-H3 & 67.10 & 0.45 & 14.90 & 5.75 & 0.06 & 1.07 & 0.80 & 0.17 & 2.66 & 0.07 & 93.04 & 6.64 \\
\hline & EIX-H4 & 76.12 & 0.21 & 5.64 & 2.71 & 0.06 & 0.69 & 5.38 & 0.47 & 1.65 & 0.13 & 93.05 & 5.63 \\
\hline & EIX-H5 & 71.93 & 0.50 & 13.03 & 4.74 & 0.02 & 1.11 & 0.40 & 0.12 & 2.94 & 0.07 & 94.85 & 4.52 \\
\hline & EX-H2 & 74.65 & 0.26 & 6.45 & 2.99 & 0.08 & 0.71 & 5.65 & 0.23 & 2.08 & 0.11 & 93.20 & 6.04 \\
\hline & EX-H4 & 73.64 & 0.24 & 6.37 & 3.02 & 0.08 & 0.77 & 6.47 & 0.27 & 1.95 & 0.10 & 92.90 & 7.13 \\
\hline & EXI-H1 & 71.41 & 0.28 & 5.73 & 2.95 & 0.08 & 0.75 & 3.18 & 0.19 & 1.70 & 0.13 & 86.41 & 13.58 \\
\hline & EXI-H2 & 77.23 & 0.26 & 6.16 & 3.19 & 0.07 & 0.73 & 4.35 & 0.20 & 1.73 & 0.08 & 93.99 & 6.19 \\
\hline & EXI-H3 & 77.13 & 0.33 & 5.30 & 2.72 & 0.07 & 0.60 & 5.80 & 0.14 & 1.95 & 0.11 & 94.14 & 6.25 \\
\hline & EXI-H4 & 73.67 & 0.23 & 6.28 & 2.88 & 0.10 & 0.79 & 6.05 & 0.23 & 1.93 & 0.08 & 92.26 & 6.48 \\
\hline & EXI-H5 & 65.36 & 0.70 & 13.87 & 5.97 & 0.06 & 1.37 & 0.92 & 0.75 & 1.77 & 0.13 & 90.90 & 7.91 \\
\hline & EXI-H6 & 69.24 & 0.26 & 14.84 & 3.07 & 0.03 & 1.82 & 0.28 & 0.36 & 3.62 & 0.07 & 93.58 & 4.56 \\
\hline & EXII-H1 & 78.07 & 0.40 & 7.61 & 3.30 & 0.06 & 0.61 & 0.58 & 0.24 & 1.30 & 0.10 & 92.26 & 7.08 \\
\hline & EXII-H3 & 91.91 & 0.03 & 2.13 & 0.65 & 0.04 & 0.27 & 1.53 & 0.11 & 1.10 & 0.02 & 97.79 & 1.96 \\
\hline & EXII-H4 & 70.08 & 0.60 & 12.85 & 4.26 & 0.05 & 0.93 & 0.90 & 0.28 & 1.80 & 0.10 & 91.85 & 7.06 \\
\hline & EXIII-H1 & 78.28 & 0.22 & 5.86 & & 0.08 & 0.61 & 4.48 & 0.10 & 1.75 & 0.09 & 94.32 & 5.06 \\
\hline & EXIII-H4 & 73.13 & 0.26 & 6.83 & 3.02 & 0.09 & 0.75 & 6.25 & 0.14 & 2.07 & 0.09 & 92.64 & 6.84 \\
\hline & EV-H1 & 75.41 & 0.30 & 6.85 & 3.18 & 0.07 & 0.67 & 3.01 & 0.37 & 1.34 & 0.14 & 91.33 & 9.06 \\
\hline & EV-H2 & 75.63 & 0.24 & 6.06 & 3.04 & 0.07 & 0.65 & 5.79 & 0.25 & 1.36 & 0.11 & 93.20 & 6.46 \\
\hline & EV-H3A & 83.70 & 0.16 & 3.80 & 2.14 & 0.05 & 0.47 & 4.22 & 0.22 & 0.99 & 0.09 & 95.83 & 4.25 \\
\hline & EV-H4 & 78.64 & 0.18 & 4.59 & 2.42 & 0.06 & 0.57 & 5.86 & 0.12 & 1.29 & 0.09 & 93.80 & 5.82 \\
\hline & EV-H5 & 71.36 & 0.23 & 6.48 & 3.37 & 0.10 & 0.69 & 7.55 & 0.21 & 1.51 & 0.12 & 91.61 & 7.45 \\
\hline & EV-H6 & 64.35 & 1.08 & 15.56 & 4.77 & 0.12 & 0.60 & 2.29 & 1.99 & 1.22 & 0.06 & 92.02 & 6.97 \\
\hline & EVII-H1 & 88.29 & 0.10 & 3.34 & 1.44 & 0.05 & 0.46 & 2.44 & 0.08 & 0.88 & 0.06 & 97.14 & 3.02 \\
\hline & EVII-H3 & 89.07 & 0.11 & 3.15 & 1.32 & 0.04 & 0.41 & 1.88 & 0.09 & 0.82 & 0.06 & 96.95 & 2.60 \\
\hline & EVII-H4 & 88.61 & 0.09 & 3.14 & 1.40 & 0.08 & 0.40 & 1.91 & 0.10 & 0.86 & 0.05 & 96.63 & 2.67 \\
\hline & EVII-H5 & 59.24 & 1.35 & 18.41 & & 0.09 & 0.99 & 1.62 & 1.33 & 1.17 & 0.12 & 91.74 & 8.77 \\
\hline & EVII-H6 & 62.25 & 1.88 & 13.86 & 10.31 & 0.41 & 0.58 & 0.82 & 1.09 & 1.33 & 0.08 & 92.62 & 7.74 \\
\hline & EVII-H7 & 58.77 & 1.36 & 18.02 & 7.73 & 0.13 & 1.12 & 1.92 & 1.62 & 1.29 & 0.12 & 92.07 & 6.86 \\
\hline & ME07m & 86.76 & 0.11 & 3.62 & 1.35 & 0.04 & 0.46 & 2.16 & 0.65 & 1.00 & 0.06 & 96.20 & 3.59 \\
\hline & $\mathrm{ME07c}$ & 82.70 & 0.15 & 4.49 & & 0.05 & 0.59 & 4.05 & 0.14 & 1.33 & 0.07 & 95.35 & 4.25 \\
\hline & EVIII-H1 & 88.95 & 0.11 & 3.41 & 1.53 & 0.04 & 0.46 & 2.21 & 0.32 & 0.89 & 0.06 & 97.97 & 2.69 \\
\hline & EVIII-H2 & 60.07 & 1.10 & 18.32 & 6.03 & 0.06 & 1.06 & 1.87 & 1.34 & 1.26 & 0.17 & 91.26 & 8.83 \\
\hline & EVIII-H3 & 88.04 & 0.14 & 3.83 & 1.70 & 0.04 & 0.45 & 1.80 & 0.19 & 0.96 & 0.07 & 97.22 & 2.54 \\
\hline & EVIII-H4 & 55.86 & 1.22 & 20.89 & 6.96 & 0.04 & 0.77 & 0.86 & 1.79 & 1.42 & 0.07 & 89.87 & 9.74 \\
\hline & EXIV-H2 & 69.22 & 0.46 & 10.45 & 3.92 & 0.08 & 0.62 & 4.85 & 0.57 & 0.93 & 0.17 & 91.26 & 8.11 \\
\hline & EXIV-H8 & 69.51 & 0.22 & 6.48 & 3.15 & 0.08 & 0.83 & 8.28 & 0.16 & 1.69 & 0.11 & 90.50 & 8.05 \\
\hline
\end{tabular}

Au y Ag son similares en todo el DIMITO, mientras que es notable el incremento en un orden de hasta 2 a 5 de los valores de $\mathrm{Zn}-\mathrm{Pb}$, para las estaciones de El Oro. Finalmente, en relación con otros distritos mineros del país, se observa que los EPT de los jales DIMITO, incluyendo los valores de hierro, se agrupan bien con los datos de los distritos mineros epitermales de Guanajuato y Taxco (excepto $\mathrm{Pb}$ y As para este último), mientras que en general muestran claras diferencias con los distritos de Zimapan, Nacozari y Santa Bárbara, en congruencia con su naturaleza metalogénica diversa.

\section{DISCUSIÓN}

Balance de acidez y neutralización (ABA) de los jales del DIMITO

El balance de acidez (ABA) se refiere al uso de las bases de datos geoquímicas con la finalidad de predecir el riesgo de la generación de acidez de un yacimiento o un sistema de resiudos mineros (Paktunc 1999; Jambor 2003; Price, 2009). Para realizar el cálculo ABA fueron seleccionadas las muestras de cada horizonte basal de los 12 perfiles (ver Figura 4), considerando que en estos niveles se registraron los 
valores más bajos de $\mathrm{pH}$ y las mayores concentraciones de sulfuros (e.g. EIII, EVIIl, VIII). Por medio del programa ModAn (Paktunc, 1998) se calcularon las proporciones modales de los minerales teóricos de los horizontes seleccionados (Tabla 6). El cálculo se basa en la normalización de la composición química de elementos mayores y se aplica una técnica de eliminación gaussiana y de regresión múltiple en el balance estequiométrico de las ecuaciones que involucran las fases previamente identificadas por petrografía. Se determinaron los valores teóricos de potencial de acidez (PA) y potencial de neutralización (PN) para cada horizonte. Los valores teóricos $\left(\mathrm{ABA}_{1}\right)$, se refieren sólo a los carbonatos presentes según la ecuación 1 :

$$
\begin{aligned}
& 4 \mathrm{FeS}_{2}(\mathrm{~s})+8 \mathrm{CaCO}_{3}(\mathrm{~s})+15 \mathrm{O}_{2}(\mathrm{~g})+6 \mathrm{H}_{2} \mathrm{O} \rightarrow \\
& 4 \mathrm{Fe}(\mathrm{OH})_{3}(\mathrm{~s})+8 \mathrm{SO}_{4}^{2-}(\mathrm{aq})+8 \mathrm{Ca}^{2+}(\mathrm{aq})+8 \mathrm{CO}_{2}
\end{aligned}
$$

Sin embargo, para considerar otras especies minerales que al disolverse podrían generar una relativa neutralización, se realizó una corrección de calcita + silicatos ó $\mathrm{ABA}_{2}$ que incluye el valor de los Al-silicatos (Jambor et al., 2004; plagioclasa, anfíbol, clorita, etc.), relacionados con la ecuación general 2:

$\mathrm{CaAl}_{2} \mathrm{Si}_{2} \mathrm{O}_{8}(\mathrm{~s})+2 \mathrm{H}^{+}(\mathrm{aq})+\mathrm{H}_{2} \mathrm{O} \rightarrow \mathrm{Ca}^{2+}+\mathrm{Al}_{2} \mathrm{Si}_{2} \mathrm{O}_{5}(\mathrm{OH})_{4}(\mathrm{~s})$

A pesar de la baja tasa de intemperismo y de los bajos valores de neutralización de los silicatos de aluminio (e.g. feldespatos, anfíboles) respecto a los carbonatos, en algunos horizontes (e.g. EIX, EX, EV, XIV) se observa que su abundancia relativa podría influir para estabilizar las muestras en correspondencia con bajos contenidos de $\mathrm{CaCO}_{3}$, o bien en la perspectiva de un mayor tiempo de exposición e intemperismo de los jales.

En la Tabla 6 y en la Figura 12 se presentan los resultados del cálculo de potencial de neutralización $\left(\mathrm{PN}_{1}\right.$ y $\left.\mathrm{PN}_{2}\right)$, potencial de acidez (PA), así como los cocientes de neutralización $\left(\mathrm{ABA}_{1}\right.$ y $\left.\mathrm{ABA}_{2}\right)$. En general se observa que los jales del DIMITO muestran valores de $\mathrm{PA}$ muy bajos (8.5-27 $\left.\mathrm{Kg}_{\mathrm{CaCO} 3} / \mathrm{ton}\right)$, en correspondencia con un alto potencial de neutralización (76.1-155.2 $\mathrm{Kg}_{\mathrm{CaCO} 3} /$ ton), excepto en dos

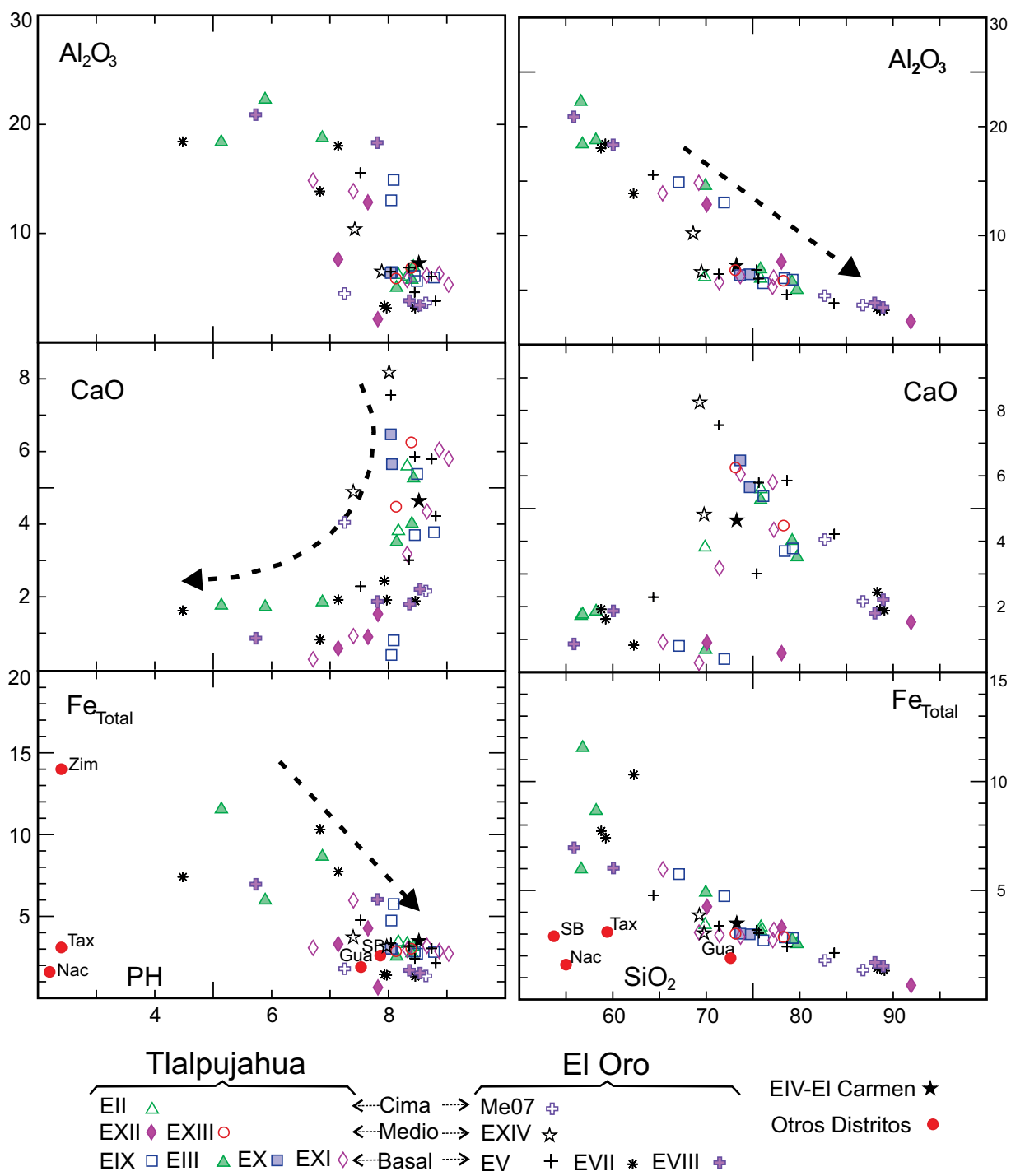

Figura 10. Diagramas comparativos entre las concentraciones (\%wt) de los elementos mayores $\mathrm{SiO}_{2}, \mathrm{Al}_{2} \mathrm{O}_{3}, \mathrm{CaO}_{\mathrm{O}}$ y $\mathrm{Fe}_{\text {Total }}$ y el pH de los jales del DIMITO. Notar los grupos de símbolos por ubicación de cima, intermedio y base del perfil o estación de los jales del DIMITO (Ver Figura 2 y Figura 4). Para su comparación se incluye la proyección de los datos de otros distritos mineros del país (Guanajuato (Ramos-Arroyo et al., 2004); Taxco (Talavera et al., 2005; Armienta et al. 2003); Zimapán (Armienta y Segovia, 2008) y Santa Bárbara (Martín-Romero et al., 2008). 


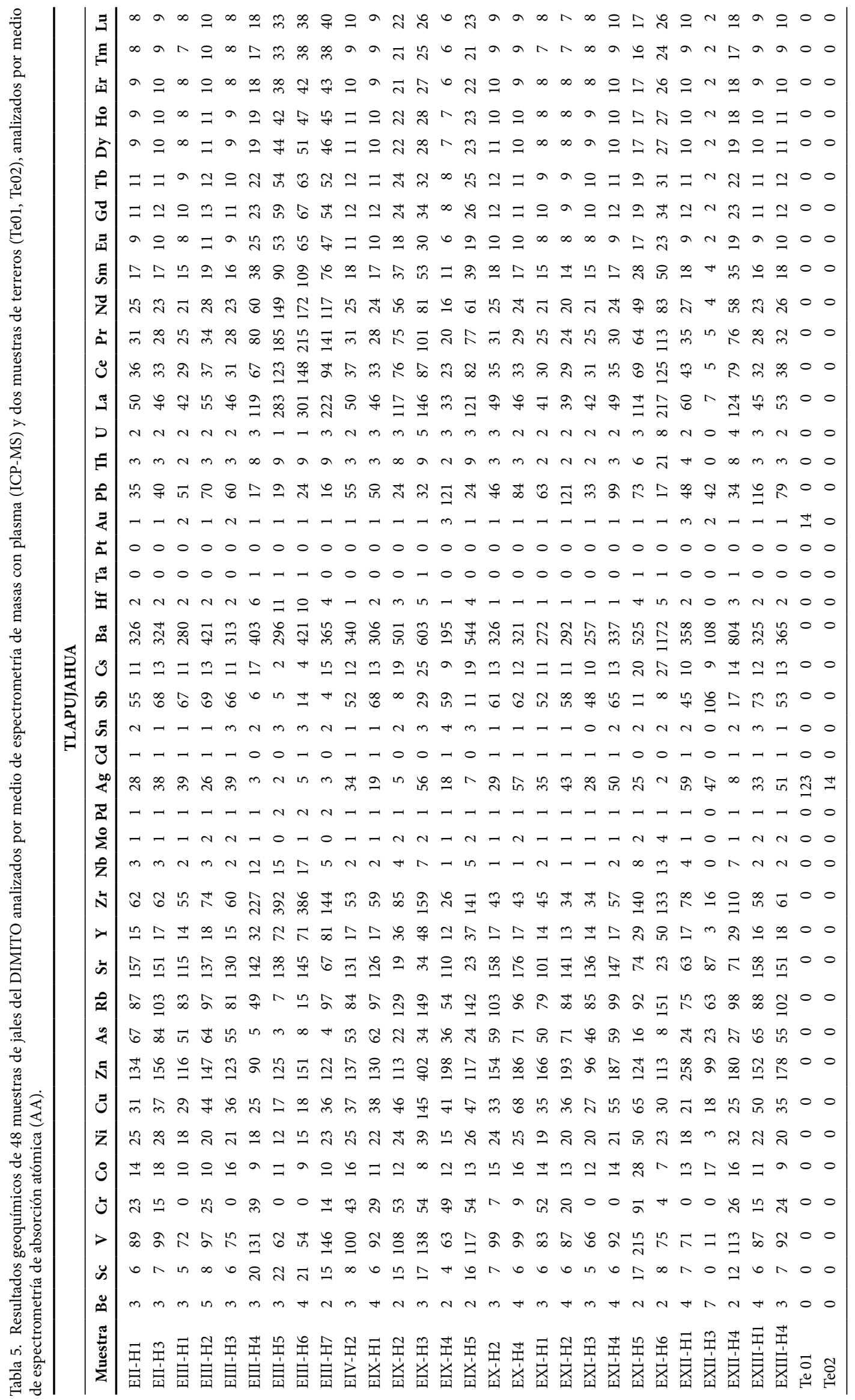

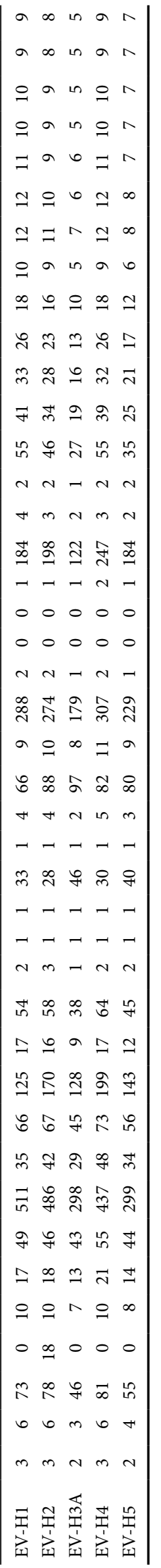




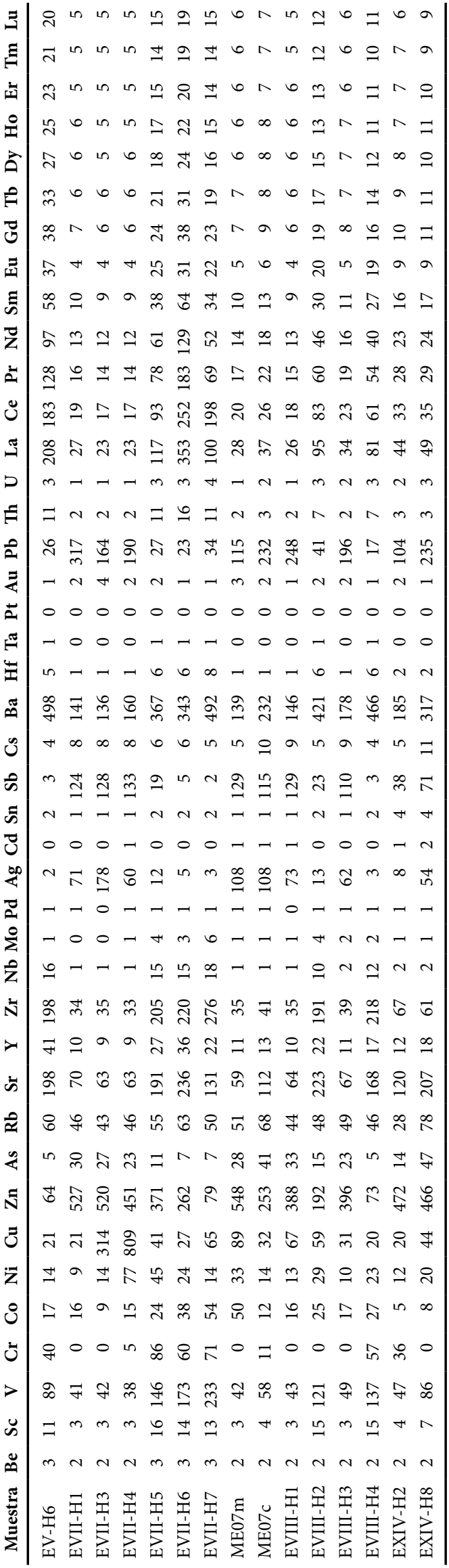

estaciones (EIII y EXI), que muestran los valores más bajos de $\mathrm{PN}$ (49-51.5 $\mathrm{Kg}_{\mathrm{CaCO} 3} /$ ton). Los cocientes $\mathrm{ABA}_{1}$ y $\mathrm{ABA}_{2}$ de todas las muestras se encuentran con valores $\mathrm{PN} / \mathrm{PA}$ de una completa neutralización (Figura 12a). En la figura 12b se presentan los datos proyectados en el diagrama de Smart (2002), en el que se observa que todas las muestras se agrupan en el campo de "no acidez", incluso por debajo de los radios $\mathrm{PN} / \mathrm{PA}=2$. Es decir, que el modelo matemático sugiere un relativo bajo o nulo riesgo en la generación de drenaje ácido para los jales del DIMITO. Este resultado se debe esencialmente a un bajo contenido modal y normativo de sulfuros que da lugar a los valores bajos de PA y que se mantienen siempre muy inferiores a los valores del PN. Sin embargo, es importante asumir que este hipotético y optimista bajo potencial de generación DAM, por su misma simplicidad, requiere ser constatado y comparado con los valores de un muestreo de agua a lo largo de los cauces fluviales naturales y drenaje de mina. Del mismo modo, es importante señalar que el bajo riesgo de generación de DAM no excluye a priori el riesgo de la movilidad de los EPT. De hecho, ha sido bien reconocido desde hace años que un sistema de jales de neutro o alcalino, similar a los jales DIMITO, puede estar asociado al decremento de la concentración $\left(\mathrm{SO}_{4}\right)^{2+}$ y del Eh, los cuales generan condiciones para la liberación de EPT a través de los poros de agua (Moncur et al., 2015; Parbhakar-Fox, 2017). Por lo tanto, particular atención requeriría el $\mathrm{Sb}$, por registrar concentraciones muy superiores a los LMP, así como el $\mathrm{Pb}$ y el As por su reconocida movilidad en suelos y agua, así como por la toxicidad de su eventual ingestión.

\section{Intemperismo, oxidación de sulfuros y minerales secundarios}

El principal factor que influye en la transformación y alteración de los jales del DIMITO se refiere al clima. Los factores determinantes son: una precipitación media $\geq 800 \mathrm{~mm} /$ año, la condición torrencial del 67 $\%$ de la lluvia concentrada en tres meses (Martínez-Medina, 2009), así como las geoformas con fuertes pendientes, dando origen a un intenso proceso de erosión activo de los depósitos de jales deleznables. Los numerosos canales y cárcavas de erosión (Figura 3f) representan ya sea una vía de transporte fluvial como una tendencia natural para la pérdida de volumen. Si se considera que se ha documentado un volumen mínimo histórico de 60 Mt de jales en el DIMITO (Uribe-Salas, 2008), así como la estimación de la pérdida de su volumen original en al menos el 27 \% (Corona-Chávez et al., 2010), implicaría que actualmente restarían aproximadamente $43.8 \mathrm{Mt}$ distribuidas en un área de $622,764.22 \mathrm{~m}^{2}$, correspondiente al área actual mapeada para las cinco áreas de depósitos de jales del DIMITO. Por otro lado, considerando la pérdida mínima de ese volumen hasta el año de 2008, es decir durante al menos 60 años, también representaría una tasa de erosión de aproximadamente 230 ton/año de material que se transportaría gradualmente hacia el depocentro de la cuenca hidrológica. Por lo tanto, en cualquier interpretación o plan de manejo de residuos mineros, es necesario considerar la separación activa grano a grano por erosión de los jales del DIMITO.

En relación con la influencia del tamaño de grano, los jales del DIMITO presentan un predominio de tipo limoso ( $>75 \%$; Figura 5 ). Estas dimensiones de grano, asociadas con una estructura deleznable, implican que las fracciones finas entre 4 y $64 \mu \mathrm{m}$ puedan ser fácilmente removidas durante el proceso de infiltración y circulación (seepage) de agua. La fracción fina estaría además constiuida en gran parte por el material fino calcáreo-carbonoso y arcilloso, con altos valores de sulfuros reportados en los ensayes metalúrgicos (Aguilar-Contreras, 1971), por lo cual su remoción hacia las zonas bajas de la cuenca hidrológica, daría lugar a una fuerte dispersión de contaminantes en estado sólido, así como también una notable disminución in situ de las concentraciones de sulfuros como la galena, esfalerita y de la pirita. Sin embargo, los resultados de granulometría y de análisis químicos de los 


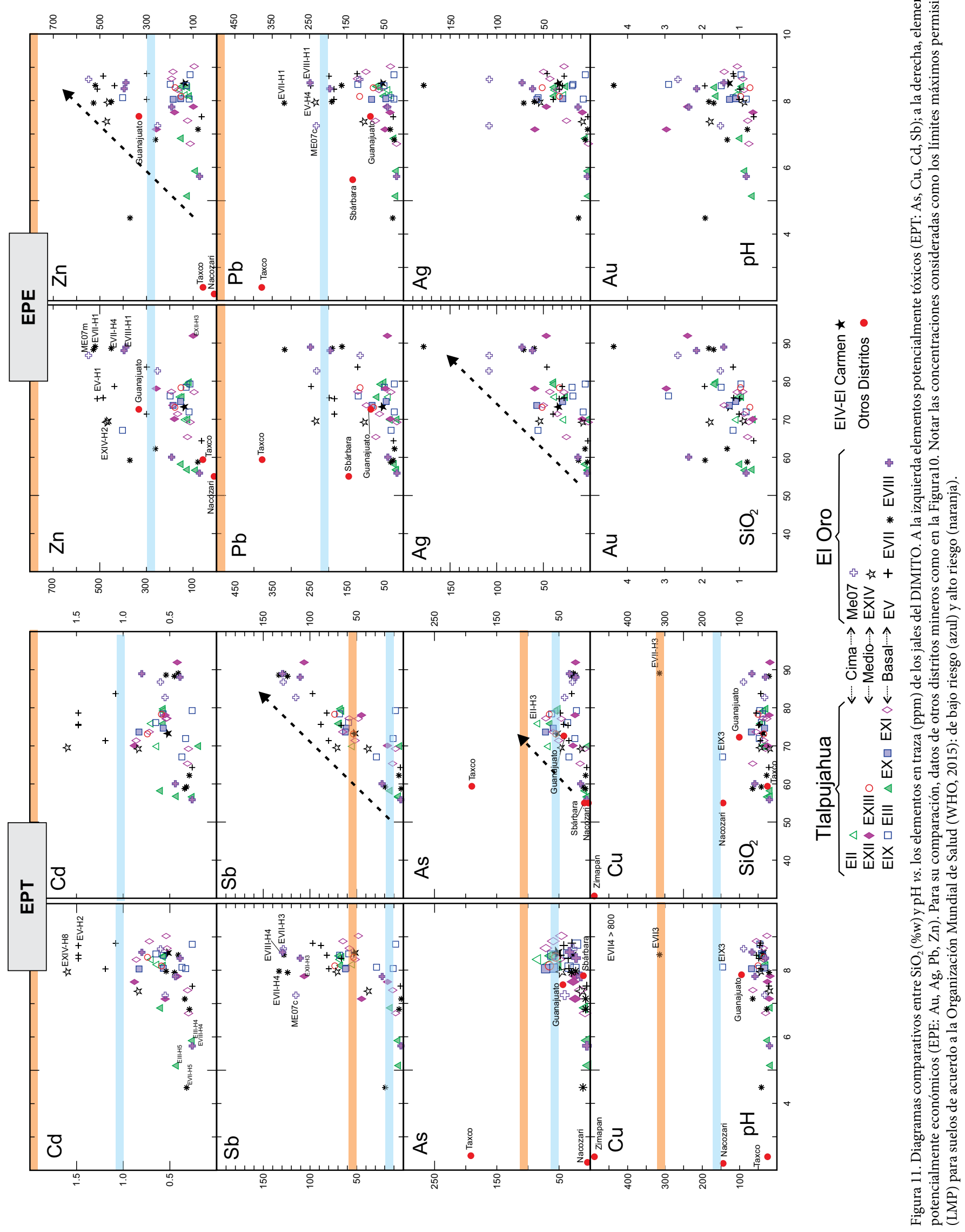


jales indican que existe aún una abundante fracción fina de material remanente, la cual incrementaría la tasa de disolución y la superficie potencial de reacción de los minerales (Jambor 2003; Jamieson et al. 2015). Por lo tanto, se requeriría hacer un estudio específico de separación secuencial, con la finalidad de ponderar el efecto y el consumo molar de la matriz calcáreo-arcillosa de los jales DIMITO.

En relación con la alteración de los clastos $>64 \mu \mathrm{m}$ o arenas finas, con base en el análisis mineralógico es posible resaltar un proceso de intemperismo selectivo en los jales DIMITO. Los tectosilicatos (cuarzo y feldespatos), así como los óxidos y los sulfuros incluidos en el cuarzo bajo forma de inclusiones, se encuentran relativamenten bien preservados.
Por su parte, los clastos de los líticos y de las sulfosales muestran una alteración heterogénea; varían desde un delgado borde de oxidación de hematita-goethita, hasta un aspecto poroso o esqueletal, con texturas lamelares con pequeños nucleos relictos. Las texturas de mayor alteración son mucho más comunes en los fragmentos aislados de pirita y de algunos óxidos con dimensiones de 64-300 $\mu \mathrm{m}$ (Figuras 6f, 8c). De acuerdo al Indice de Alteración de los Sulfuros (SAI), propuesto por Moncur et al. (2005), mientras que los granos aislados de pirita y óxidos exhibirían un SAI $>6$, los líticos, tectosilicatos y los granos encapsulados de sulfuros en cuarzo podrían corresponder a un $\mathrm{SAI} \leq 2$. En relación con los procesos de alteración y la precipitación de minerales secundarios,

Tabla 6. Estimación de la mineralogía normativa y del potencial de neutralización (PN) y acidez (PA), así como su balance ácido-base (ABA), utilizando los softwares ModAn y mNP y el método de Paktunc $(1998 ; 1999 ; 2003)$. Las concentraciones de los elementos mayores en óxidos (\%wt). PN1 y ABA1 corresponden al cálculo sin considerar la influencia de neutralización los silicatos. PN2, ABA2 corresponden al cálculo con las correcciones del PN de calcita+silicatos para los Al-silicatos usados por Jambor et al. (2004). Abreviaciones: calcita (Cal); cuarzo (Qz); ortoclasa (Ort); hornblenda (Hn), ilmenita (Ilm); hematita (Hem); illita (Ilt), albita (Alb); rodocrosita (Rod); clorita (Clt); pirita (Py).

\begin{tabular}{|c|c|c|c|c|c|c|c|c|c|c|c|c|}
\hline Elemento & EII-H3 & EIII-H7 & EIV-H2 & EIX-H5 & EX-H4 & EXI-H6 & EXII-H4 & EXIII-H4 & EV-H6 & EVII-H7 & EVIII-H4 & EXIV-H8 \\
\hline $\mathrm{SiO}_{2}$ & 75.85 & 69.95 & 73.27 & 71.93 & 73.64 & 69.24 & 70.08 & 73.13 & 64.35 & 58.77 & 55.86 & 69.51 \\
\hline $\mathrm{TiO}_{2}$ & 0.25 & 0.44 & 0.35 & 0.50 & 0.24 & 0.26 & 0.60 & 0.26 & 1.08 & 1.36 & 1.22 & 0.22 \\
\hline $\mathrm{Al}_{2} \mathrm{O}_{3}$ & 6.05 & 14.56 & 7.27 & 13.03 & 6.37 & 14.84 & 12.85 & 6.83 & 15.56 & 18.02 & 20.89 & 6.48 \\
\hline $\mathrm{FeOt}$ & 3.31 & 4.90 & 3.49 & 4.74 & 3.02 & 3.07 & 4.26 & 3.02 & 4.77 & 7.73 & 6.96 & 3.15 \\
\hline $\mathrm{MnO}$ & 0.08 & 0.02 & 0.08 & 0.02 & 0.08 & 0.03 & 0.05 & 0.09 & 0.12 & 0.13 & 0.04 & 0.08 \\
\hline $\mathrm{MgO}$ & 0.68 & 1.41 & 0.93 & 1.11 & 0.77 & 1.82 & 0.93 & 0.75 & 0.60 & 1.12 & 0.77 & 0.83 \\
\hline $\mathrm{CaO}$ & 5.59 & 0.68 & 4.64 & 0.40 & 6.47 & 0.28 & 0.90 & 6.25 & 2.29 & 1.92 & 0.86 & 8.28 \\
\hline $\mathrm{Na}_{2} \mathrm{O}$ & 0.13 & 0.14 & 0.26 & 0.12 & 0.27 & 0.36 & 0.28 & 0.14 & 1.99 & 1.62 & 1.79 & 0.16 \\
\hline $\mathrm{K}_{2} \mathrm{O}$ & 2.00 & 2.39 & 1.86 & 2.94 & 1.95 & 3.62 & 1.80 & 2.07 & 1.22 & 1.29 & 1.42 & 1.69 \\
\hline $\mathrm{P}_{2} \mathrm{O}_{5}$ & 0.11 & 0.07 & 0.12 & 0.07 & 0.10 & 0.07 & 0.10 & 0.09 & 0.06 & 0.12 & 0.07 & 0.11 \\
\hline Suma & 94.04 & 94.55 & 92.26 & 94.85 & 92.90 & 93.58 & 91.85 & 92.64 & 92.02 & 92.07 & 89.87 & 90.50 \\
\hline $\mathrm{P} \times \mathrm{C}$ & 5.85 & 5.06 & 7.05 & 4.52 & 7.13 & 4.56 & 7.06 & 6.84 & 6.97 & 6.86 & 9.74 & 8.05 \\
\hline S & 0.34 & 0.70 & 0.46 & 0.55 & 0.38 & 0.91 & 0.47 & 0.37 & 0.30 & 0.56 & 0.38 & 0.41 \\
\hline $\mathrm{CO} 2$ & 4.39 & 3.80 & 5.29 & 3.39 & 5.35 & 3.42 & 5.30 & 5.13 & 5.23 & 5.15 & 7.31 & 6.04 \\
\hline \multicolumn{13}{|c|}{ Mineralogía modal calculada (Paktunc, 2001) } \\
\hline Cal & 9.45 & 3.19 & 9.15 & 6.81 & 11.17 & 2.13 & 4.64 & 11.45 & 6.41 & 5.83 & 5.88 & 13.98 \\
\hline $\mathrm{Qz}$ & 63.29 & 44.73 & 59.45 & 45.33 & 60.18 & 40.89 & 47.56 & 61.90 & 32.33 & 22.83 & 14.51 & 57.68 \\
\hline Ort & 7.28 & 0.00 & 4.72 & 4.77 & 6.42 & 7.85 & 0.00 & 0.00 & 0.00 & 0.00 & 0.00 & 4.53 \\
\hline $\mathrm{Hn}$ & 3.84 & 1.84 & 2.17 & 6.32 & 3.85 & 4.07 & 0.00 & 3.26 & 0.00 & 0.29 & 0.00 & 5.51 \\
\hline Ilm & 0.39 & 0.77 & 0.59 & 0.68 & 0.40 & 0.39 & 1.14 & 0.49 & 2.04 & 2.58 & 2.20 & 0.30 \\
\hline Hem & 2.17 & 3.96 & 2.76 & 3.31 & 2.37 & 1.65 & 0.57 & 2.37 & 1.36 & 6.78 & 2.20 & 2.36 \\
\hline Ilt & 12.20 & 41.16 & 17.32 & 31.61 & 12.85 & 37.11 & 30.60 & 19.64 & 30.87 & 42.22 & 42.16 & 14.86 \\
\hline Alb & 0.49 & 1.35 & 1.87 & 0.00 & 1.68 & 2.42 & 2.65 & 0.00 & 16.12 & 16.91 & 17.64 & 0.00 \\
\hline Rod & 0.30 & 1.74 & 1.08 & 0.19 & 0.40 & 1.84 & 2.27 & 0.20 & 1.84 & 2.01 & 3.21 & 0.00 \\
\hline Clt & 0.00 & 0.00 & 0.00 & 0.00 & 0.00 & 0.00 & 9.66 & 0.00 & 8.45 & 0.00 & 11.67 & 0.00 \\
\hline Py & 0.59 & 1.26 & 0.89 & 0.97 & 0.69 & 1.65 & 0.89 & 0.69 & 0.58 & 0.57 & 0.52 & 0.79 \\
\hline Suma & 100.00 & 100.00 & 100.00 & 100.00 & 100.00 & 100.00 & 100.00 & 100.00 & 100.00 & 100.00 & 100.00 & 100.00 \\
\hline \multicolumn{13}{|c|}{ Corrección Calcita+Silicatos(\%Calcita; Paktunc, 2001; 2003; Jambor et al., 2004)) } \\
\hline & 11.23 & 4.9045 & 11.106 & 8.7085 & 13.159 & 5.1502 & 7.6118 & 12.277 & 11.878 & 10.885 & 12.762 & 15.521 \\
\hline \multicolumn{13}{|c|}{ Potencial de Neutralización/Acidez y Balance de Neutralización (Paktunc, 2003) } \\
\hline $\mathrm{PN}_{1}\left(\mathrm{KgCaCO}_{3} \mathrm{req} / \mathrm{t}\right)$ & 97 & 47 & 100.8 & 69.7 & 115.1 & 37.3 & 66.1 & 116.1 & 80.1 & 75.7 & 86.7 & 39.7 \\
\hline $\mathrm{PA}_{1}\left(\mathrm{KgCaCO}_{3} \mathrm{req} / \mathrm{t}\right)$ & 9.6 & 20.6 & 14.5 & 15.8 & 11.3 & 27 & 14.5 & 11.3 & 9.5 & 9.3 & 8.5 & 12.9 \\
\hline $\mathrm{ABA}_{1}\left(\mathrm{KgCaCO}_{3} \mathrm{req} / \mathrm{t}\right)$ & 87.4 & 26.4 & 86.3 & 53.9 & 103.8 & 10.3 & 51.6 & 104.8 & 70.6 & 66.4 & 78.2 & 26.8 \\
\hline \multicolumn{13}{|c|}{ Potencial de Neutralización/Acidez y Balance de Neutralización (Paktunc, 2003; Jambor et al., 2004) } \\
\hline $\mathrm{PN}_{2}\left(\mathrm{KgCaCO}_{3} \mathrm{req} / \mathrm{t}\right)$ & 112.2 & 49 & 111 & 87.08 & 131.05 & 51.5 & 76.1 & 122.8 & 118.8 & 108.9 & 127.6 & 155.2 \\
\hline $\mathrm{PA}_{2}\left(\mathrm{KgCaCO}_{3} \mathrm{req} / \mathrm{t}\right)$ & 9.6 & 20.6 & 14.5 & 15.8 & 11.3 & 27 & 14.5 & 11.3 & 9.5 & 9.3 & 8.5 & 12.9 \\
\hline $\mathrm{ABA}_{2}\left(\mathrm{KgCaCO}_{3} \mathrm{req} / \mathrm{t}\right)$ & 102.6 & 28.4 & 96.5 & 71.28 & 119.75 & 24.5 & 61.6 & 111.5 & 109.3 & 99.6 & 119.1 & 142.3 \\
\hline \multicolumn{13}{|c|}{ Potencial de Drenaje Acido (Paktunc, 2003) } \\
\hline Potencial DAM & No & bajo & No & No & No & posible & No & No & No & No & No & No \\
\hline
\end{tabular}


el clima templado-frío y la precipitación entre 800 y 1,100 mm anuales de agua del DIMITO, conforman un sistema hidrodinámico extraordinario que podría afectar en forma drástica los procesos de oxidación, de disolución y, por lo tanto, la precipitación de minerales secundarios. Un sistema de alta energía hidraúlica, ya sea por infiltración o circulación y escorrentía aparentemente no favorecería los procesos de reacción relativamente lentos y, en particular, la estabilidad de la precipitación de los minerales secundarios (Blowes y Jambor, 1994; Parbhakar-Fox, 2017). Así mismo, algunos procesos de oxidación e hidrólisis para la disolución de los cationes $\left(\mathrm{Fe}^{2+}\right)$ entre poros serían intermitentes y en muchos casos, las superficies de los minerales secundarios podrían ser removidas por disolución en los flujos de circulación del sistema del jal. Este proceso hidrodinámico, podría explicar por qué los jales del DIMITO, excepto tres delgados horizontes basales (EIII, EVII, EVIII), muestran una relativa homogeneidad ligeramente alcalina, independientemente de su posición vertical. Además, no se observaron crestones de grandes dimensiones (hardpan), como tampoco se identificaron sulfatos en campo, ya sea en las delgadas costras blanquecinas generadas por eflorescencia como en microscopía en los bordes de grano. En las costras de eflorescencia predominan por su abundancia minerales secundarios como: calcita $\left(\mathrm{CaCO}_{3}\right)$ y arcillas (caolinita $\mathrm{Al}_{2} \mathrm{Si}_{2} \mathrm{O}_{5}(\mathrm{OH})_{4}$, como en lixiviados se observó esmectita $\mathrm{Al}_{2} \mathrm{O}_{5} 4 \mathrm{SiO}_{2} \mathrm{xH}_{2} \mathrm{O}$ ), y sílice (amorfa, cristobalita $\alpha \mathrm{SiO}_{2}$ ). Por su parte, los hidróxidos (goethite $\alpha-\mathrm{FeOOH}$; hematita ferrihidrita $\mathrm{Fe}_{5} \mathrm{HO}_{8}$ ) se observaron en las costras, y son más abundantes en algunos flóculos donde hay mayor flujo de agua.

Por último, en relación con algunos horizontes basales de los jales DIMITO con $\mathrm{pH}<6$ y que muestran una relación $\mathrm{PN} / \mathrm{PA} \approx 2$ (EIII, EIX, EXI, EXII), es importante hacer notar que sus valores calculados de ABA se deben realmente a un bajo PN, más que a un valor anómalo de PA; es decir, que estos horizontes presentan una relativa deficiencia de carbonatos, más que una mayor abundancia de sulfuros. Aunque esta variación de alcalinidad podría ser interpretada como un simple decremento de calcita (bulk), es importante hacer notar su coincidente posición basal. Su importancia radica en que señalaría la presencia de un proceso de lixiviación y diferenciación geoquímica activos relacionados con la circulación del agua de los jales. Por lo tanto, resulta relevante estimar la variación temporal e in situ de la composición del agua y de los horizontes basales de los jales del DIMITO.

\section{CONCLUSIONES}

\section{Panorama actual y manejo de los residuos mineros del DIMITO}

Con base en la cartografía, se observa que los jales del DIMITO presentan volúmenes variables relacionados con la paleo-topografía de las cañadas donde fueron depositados, así como por el efecto de una intensa disección de erosión durante más de 68 años. Los jales del DIMITO muestran en general un $\mathrm{pH}$ de neutro a ligeramente alcalino, una granulometría prevalentemente limosa $(<45-90 \mu \mathrm{m})$, una relativa baja conductividad $(<80 \mu \mathrm{S} / \mathrm{cm})$. Su composición mineralógica muestra una predominancia de cuarzo, bajos contenidos de sulfuros y bajas concentraciones de EPT. Este ambiente ó sistema geoquímico, asociado con importantes contenidos de carbonatos (8-20\% vol), indicarían un sistema natural donde ocurren procesos de intemperismo con un bajo, a muy bajo riesgo potencial de generación de DAM. Por otro lado, a pesar del proceso de intensa erosión activa, en general los jales muestran una importante cubierta de regeneración vegetacional, con jales pedogenizados y de suelos húmedos. Esta cubierta húmeda prevendría de manera natural una serie de procesos relacionados con la infiltración, erosión y el transporte de oxígeno a través de los poros del jal (Bradshaw, 1997; Lottermoser, 2010).

Sin embargo, el presente estudio sólo representa una primera
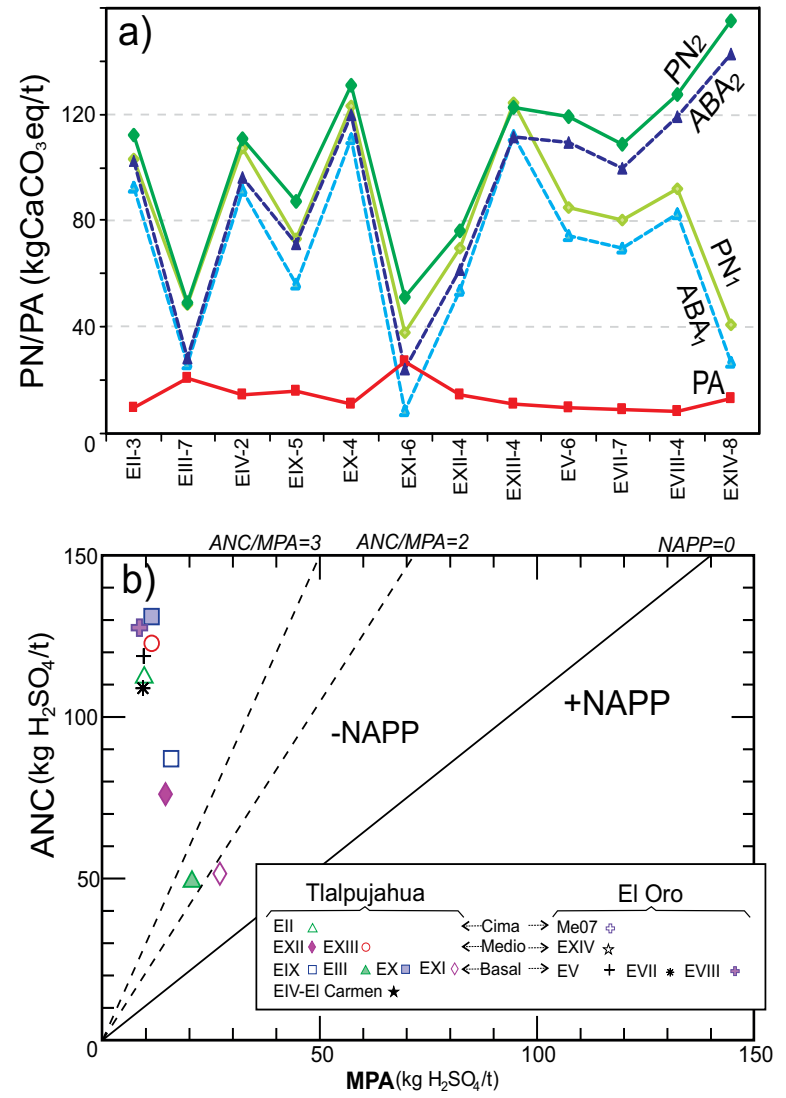

Figura 12. Diagramas que muestran las variaciones de la estimación del potencial de neutralización (PN) y acidez (PA), así como su balance ácido-base (ABA). a) Gráficas con las curvas de los cálculos para cada muestra. PN1 y ABA1 corresponden al cálculo sin considerar la influencia de neutralización los silicatos. PN2, ABA2 corresponden al cálculo con las correcciones del PN de calcita+silicatos para los Al-silicatos usados por Jambor et al. (2004). b) Diagrama de Smart et al. (2002). Por sus siglas en inglés: Potencial máximo de acidez (MPA); Capacidad de neutralización de acidez (ANC) y Potencial (positivo o negativo) neto de acidez (NAPP). Para el cálculo se utilizaron los softwares Modan y $m \mathrm{NP}$ y el método de Paktunc (1998; 1999; 2003), así como las correcciones ponderadas de PN para los Al-silicatos usados por Jambor et al. (2004).

aproximación geoquímica de los jales, por lo que resulta fundamental estudiar los procesos de liberación y movilidad de los metales a través de los poros de agua en un sistema alcalino como los jales DIMITO. Así mismo, se requiere reunir otros datos del comportamiento geoquímico de los flujos de agua generados por los jales, así como de la incorporación del drenaje de aguas de mina de vetas y socavones abandonados al sistema hidrológico del DIMITO (Nieto-Monroy, 2007).

Paradojicamente, aunque la naturaleza de la región del DIMITO muestra una tendencia que favorece la regeneración vegetacional y de un sistema biótico devastado hace 68 años, no se conoce alguna intervención institucional o ciudadana que haya considerado la problemática ambiental de post-minería. Los residuos y obras mineras hoy forman parte de un paisaje en abandono. Algunas de las áreas de los jales, incluso de los socavones con drenaje de mina han sido poco a poco ocupados por nuevas construcciones de casas, así como por cultivos domésticos (e.g. maiz, frijol). Aunque otros estudios de geoquímica serían siempre necesarios para ponderar el impacto ambiental, pero la información y comunicación con y desde los habitantes del DIMITO resulta hoy la prioridad para un correcto plan de manejo y regulación del territorio de post-minería en el DIMITO. 


\section{AGRADECIMIENTOS}

Este artículo es una contribución del fideicomiso CONACyTGobierno del Estado de Michoacán, FOMIX-2005-C01-014. Se agradece el apoyo y completa disponibilidad de la valiente dirigencia del Museo Tecnológico Mina Dos Estrellas. En particular al Mtro. Gustavo Bernal y a Carmelita subdirectora del Museo que en esos años nos brindaron su apoyo. Se agradece al Ing. Teodoro Hernández Treviño del LUGIS-UNAM, por su apoyo en el proceso de preparación de las muestras y separación de minerales. Se agradecen las sugerencias y correcciones de dos revisores anónimos, las cuales han mejorado notablemente el manuscrito, así como a Luigi Solari por el trabajo editorial.

\section{REFERENCIAS}

Aguilar Contreras, A., 1971, Reporte sobre las principales acumulaciones de jales que hay en los alrededores de a población del El Oro, Mex: Servicio Geológico Mexicano - Consejo de Recursos Minerales, Informe interno, $7 \mathrm{pp}$.

Albinson, T., Norman, D.I., Cole, D., and Chomiak, B.A, 2001, Controls on formation of low-sulfidation epithermal deposits in Mexico: constraints from fluid inclusion and stable isotope data: Society of Economic Geologists, Special Publication Series, 8, 1-32.

Armienta M.A., Segovia N, 2008, Arsenic and Fluoride in the groundwater of Mexico: Environment Geochemical and Health, 30, 345-353.

Armienta, M.A., Talavera, O., Morton, O., Barrera, 2003, Geochemistry of Metals from Mine Tailings in Taxco, Mexico: Bulletin Environmental Contamination Toxicology, 71, 387-393.

Bernal-Navarro, G., 2012, Notas y apuntes para la historia de la Mina Las Dos Estrellas: México D.F., APE Editorial, , 80 pp.

Blowes, D.W. Jambor J.L., 1994, The environmental geochemistry of sulfide mine wastes: Waterloo, Mineralogical Association of Canada, $225 \mathrm{pp}$.

Blowes D.W., Bain, J.G., Smyth, D.J., Ptacek, C.J., 2003, Treatment of mine drainage using permeable reactive materials: In: Jambor JL, Blowes DW, Ritchie AIM (eds) Environmental aspects of mine wastes, Vol 31. Mineralogical Association of Canada, Nepean, (Short course handbook), 361-376.

Blowes, D.W., Ptacek, C.J., Jambor, J.L., Weisener, C.G., Paktunc, D., Gould, W.D., Johnson, D.B., 2014, The geochemistry of acid mine drainage, en Turekian, H.D.H.K. (Ed.), Treatise on Geochemistry: Oxford, Elsevier, second ed., 131-190.

Bouzahzah, H., Benzaazoua, M. Bussiere, B., Plante, B., 2014, Prediction of Acid Mine Drainage: Importance of Mineralogy and the Test Protocols for Static and Kinetic Tests: Mine Water Environ, 33(1), 54-65.

Bradshaw, A.D., 1997, Restoration of mine-land using natural processes: Ecological Engineering, 7(8), 255-269.

Burkart, J., 1869, Descripción del distrito de Minas de Tlalpujahua y de su constitución geológica: Boletín de la Sociedad de Geografía y Estadística de la República Mexicana, segunda época, tomo 1, 82-111.

Bustamante-García, J., 2007, Inventario Físico del Municipio de Tlalpujahua: Servicio Geológico Mexicano, Informe interno, $95 \mathrm{pp}$.

Campa, M.F., Coney P.J., 1983, Tectonostratigraphic terranes and mineral resource distributions in Mexico: Canadian Journal of Earth Sciences, 20, 1040-1051.

Camprubí, A., Ferrari, L., Cosca, M., Cardellach, E., Canals, A., 2003, Ages of epithermal deposits in Mexico: regional significance and links with the evolution of tertiary volcanism: Economic Geology, 98(5), 1029-1037.

Candente Gold Corp, 2014, Candente gold announces El Oro tailings inferred resource, http://www.marketwired.com/press-release/candente-goldannounces-el-oro-tailings-inferred-resource-contains-119900-oz-gold3m-tsx-cdg-1928443.htm (Última consulta 23/07/2017).

Centeno-García, E., Corona-Chávez, P., Talavera-Mendoza, O., Iriondo, A. 2003, Geology and tectonic evolution of the western guerrero terrane: a transect from Puerto Vallarta to Zihuatanejo, en Geologic Transects Across Cordilleran Mexico, Guidebook for the fieldtrips of the 99th Geological Society of America Cordilleran Section Meeting: Publicacion especial del
Instituto de Geología y Centro de Geociencias UNAM, 201-228.

Corona-Chávez P., Uribe-Salas, J.A., 2009, Atlas cartográfico del distrito minero El Oro y Tlalpujahua: Morelia, Mich., Morevallado Editores, 105 pp.

Corona-Chávez, P., Uribe-Salas, J.A., Razo-Pérez, N., Martínez-Medina, M. Maldonado-Villanueva, R., Ramos-Arroyo Y., Robles-Camacho, J., 2010, The impact of mining in the regional ecosystem: the mining district of El Oro and Tlalpujahua, Mexico: De Re Metallica, 15, 21-34.

De la Teja-Segura, M.A., Moctezuma-Salgado, M.D., Vergara, A., 1999, Carta geológico-minera El Oro de Hidalgo E14-A16, escala 1:50,000: Servicio Geológico Mexicano Informe Técnico Clave: 151999TESM0001 (http:// www.sgm.gob.mx/), 40p. 1 mapa, consultado el 15 de noviembre de 2017.

Elvir-Aceituno, R., 1955, Informe geológico de la región auroargentífera de El Oro, México y Tlalpujahua, Michocán: México D.F., 56 pp.

Flores, T., 1920, Estudio Geológico Minero de los Distritos de El Oro y Tlalpujahua: Cd. de México, Secretaria de Gobernación, 85 pp y anexos.

Fries, C., Jr., Ross C., Obregón, A., 1965, Mezcla de vidrios en los derrames cineríticos las Américas de la Región de El Oro-Tlalpujahua, Estados de México y Michoacán, Parte Centro meridional de México: México D.F., Universidad Nacional Autónoma de México, Boletín del Instituto de Geología, 70, 1-84.

García, E., 1998, Climas (clasificación de Koppen, modificado por García): México, Comisión Nacional para el Conocimiento y Uso de la Biodiversidad (CONABIO), Escala 1:1'000,000, 1 mapa.

Hageman, P.L., Seal, R., Diehl, S.F., Piatak, N.M., Lowers, H.A., 2015, Evaluation of selected static methods used to estimate element mobility, acidgenerating and acid-neutralizing potentials associated with geologically diverse mining wastes: Applied Geochemistry, 57, 125-139.

Hernández-Bernal, M.S., Corona-Chávez, P., Solís-Pichardo, G., Schaaf, P., Solé-Viñas, J., Molina, J.F., 2016, Miocene andesitic lavas of Sierra de Angangueo: a petrological, geochemical, and geochronological approach to arc magmatism in Central Mexico: International Geology Review, 58(5), 603-625.

Jambor J.L. 1994, Mineralogy of sulfide-rich tailings and their oxidation products, en Jambor J.L., Blowes D.W. (eds.) Environmental geochemistry of sulfide mine-wastes: Mineralogical Association of Canada, Short Course Handbook , 22, 59-102.

Jambor, J.L. 2003, Mine-waste mineralogy and mineralogical perspectives of acid-base accounting, en Jambor J.L., Blowes D.W., Ritchie A.I.M. (eds.) Environmental aspects of mine wastes: Mineralogical Association of Canada, 31, 117-145.

Jambor, J.L., Blowes, D.W., 1998, Theory and applications of mineralogy in environmental studies of sulfide-baring mine waste: en Cabri, L.J., Vaughan, D.J. (eds.), Modern Approaches to Ore and Environmental Mineralogy: Ottawa, Canadá, Mineralogical Association of Canada, Short Course Series, 27, 367-401.

Jambor, J.L., Dutrizac, J.E., Groat, L.A. Raudsepp, M., 2004, Static tests of neutralization potentials of silicate and aluminosilicate minerals: Environmental Geology, 43, 1-17.

Jamieson, H.E. 2011, Geochemistry and mineralogy of solid mine waste: essential knowledge for predicting environmental impact: Elements, 7, 381-386.

Jamieson, H.E., Walker S.R., Parsons, M.B. 2015, Mineralogical characterization of mine waste: Applied Geochemistry, 57, 85-105.

Lindsay, M.B.J., Moncur, M.C., Bain J.G., Jambor, J.L., Ptacek, C.J. Blowes, D.W., 2015, Geochemical and mineralogical aspects of sulfide mine tailings: Applied Geochemistry 57, 157-177.

Lottermoser, B.G., 2010, Mine Wastes: Characterization, treatment and environmental impacts: Berlin Heilderberg, Springer-Verlang, 278 pp.

Lottermoser, B.G., 2017, Predicting Waste Properties Using the GeochemistryMineralogy-Texture-Geometallurgy Approach en Enviromental indicators in metl mining: Berlin Heilderberger, Springer, $403 \mathrm{pp}$.

Lozano-Santa Cruz R., Verma S.P., Girón P., Velasco F., Morán D., Viera F. Chávez, G., 1995, Calibración preliminar de fluorescencia de rayos X para análisis cuantitativo de elementos mayores en rocas ígneas: Actas INAGEQ, 1, 203-208.

Maldonado-Villanueva, R., 2008, Caracterización mineralógica de fases minerales metálicas en muestras de jales del distrito minero El OroTlalpujahua, México: México D.F., Universidad Nacional Autónoma de México, Facultad de Ingeniería, Tesis de Licenciatura, 89 pp. 
Macías-Vázquez, J.L., Corona-Chávez, P., Sanchéz-Núñez, J.M., MartínezMedina, M., García-Tenorio, F., Cisneros-Máximo, G., Garduño-Monroy, V.H. 2015, The may 27, 1937 catastrophic flow failure of gold tailings at Tlalpujahua, Michoacán, México: Natural Hazards and Earth System Sciences, 15, 1069-1085.

Markert, B., 1987, The pattern of distribution of lanthanide elements in soils and plants: Phytochemistry, 26(12), 3167-3170.

Martín-Romero, F., Armienta, M.A., Gutiérrez, M.E., Villaseñor, G., 2008, Factores geológicos y climáticos que determinan la peligrosidad y el Impacto ambiental de jales mineros: Revista Internacional de Contaminación Ambiental, 24(2), 43-54.

Martínez-Medina, M., 2009, Evaluación de la importancia económica (recuperación secundaria) y del efecto del impacto ambiental en la calidad del agua por residuos mineros (jales) en el distrito minero de Tlalpujahua Michoacán: Morelia, Mich., Universidad Michoacana de San Nicolás de Hidalgo, Tesis de Maestría, 115 pp.

Moncur, M.C., Ptacek, C.J., Blowes, D.W., Jambor, J.L., 2005, Release, transport and attenuation of metals from an old tailings impoundment: Applied Geochemistry, 20, 639-659.

Morales, J., Hernández-Bernal, M.S., Corona-Chávez, P., Gogichaishvili, A., Bautista. F. 2016, Further evidence for magnetic susceptibility as a proxy for the evaluation of heavy metals in mining wastes: case study of Tlalpujahua and El Oro Mining Districts: Environment Earth Sciences, 75:309, doi. org/10.1007/s12665-015-5187-8.

Nieto-Monroy, A.P., 2007, Variabilidad espacial y temporal de la hidrogeoquímica de arroyos del distrito minero El Oro-Tlalpujahua, Guanajuato: Guanajuato, Universidad de Guanajuato, Tesis de Licenciatura, $64 \mathrm{pp}$.

Paktunc, A.D., 1998, Modan: An interactive computer program for estimating mineral quantities based on bulk composition: Computer and Geosciences, $24,425-431$

Paktunc, A.D., 1999, Mineralogical constraints on the determination of neutralization potential and prediction of acid mine drainage: Environmental Geology, 39, 103-112.

Paktunc, A.D, 2001, MODAN a computer program for estimating mineral quantities based on bulk composition: windows version: Computers and Geosciences, 27, 883-886.

Paktunc, A.D., 2003, $m N P$ : A computer program to determine acid generating and neutralization potentials of mine wastes based on mineralogical composition. CANMET Division Report MMSL 03-030 (TR). https:// www.researchgate.net/profile/Dogan_Paktunc/contributions, consultado el 9 de noviembre de 2017.

Paktunc, D., Foster, A., Heald, S., Laflamme, G., 2004, Speciation and characterization of arsenic in gold ores and cyanidation tailings using X-ray absorption spectroscopy: Geochimica et Cosmochimica Acta, 68, 969-983.

Pantoja-Alor, J., 1994, Formación Las Américas, Tlalpujahua, Michoacán, México - Una reinterpretación de los datos petrográficos, petroquímicos, tectónicos y de los mecanismos de erupción: Revista Méxicana de Ciencias Geológicas, 11(2), 168-181.

Parbhakar-Fox, A., 2017, Predicting Waste Properties Using the GeochemistryMineralogy-Texture-Geometallurgy Approach, en Enviromental indicators in metl mining: Berlin Heilderberger, Springer, 55-72.

Plumlee, G.S., 1999, The environmental geology of mineral deposits, en Plumlee, G.S., Logsdon, M.J. (eds.), The Environmental Geochemistry of Mineral Deposits; Part A: Processes, Techniques, and Health Issues: Colorado, Society of Economic Geologists, Reviews in Economic Geology, 6A, 71-116.
Price, W.A., 2009, Prediction manual for drainage chemistry from sulphidic geologic materials, CANMET - Mining and Mineral Sciences Laboratories $579 \mathrm{pp}$.

Ramos-Arroyo, Y.R., Siebe-Grabach, C.D., 2006, Estrategia para identificar jales con potencial de riesgo ambiental en un distrito minero: estudio de caso en el Distrito de Guanajuato, México: Revista Mexicana de Ciencias Geológicas, 23(1), 54-74.

Ramos-Arroyo, Y.R., Prol-Ledesma, R.M., Siebe-Grabach, C., 2004, Características geológicas y mineralógicas e historia de extracción del Distrito de Guanajuato, México. Posibles escenarios geoquímicos para los residuos mineros: Revista Mexicana de Ciencias Geológicas, 21(2), 268-284.

Sanchéz-Núñez, J.M, Macías, J.L., Corona-Chávez, P., Martínez-Medina, M., Garduño-Monroy, V.H., Capra, L., García-Tenorio, F., Cisneros-Máximo, G., 2015, Rompimiento y desborde de presas de jales: el caso de estudio de Tlalpujahua (27 de mayo de 1937): Ciencia Nicolaita, 65, 95-119.

SEMARNAT (Secretaría de Medio Ambiente y Recursos Naturales), 2011, Norma Oficial Mexicana NOM-157-2009, Que establece los elementos y procedimiento para instrumentar planes de manejo de rsiduos mineros: México, Diario Oficial de la Federación, 30 agosto de 2011.

Siebe-Grabach, C.D., Jahn, R., Stahr, K., 1996, Manual para la Descripción y Evaluación Ecológica de Suelos en el Campo: Chapingo, México, Sociedad Mexicana de la Ciencia del Suelo, A.C., Publicación Especial, 4, 57 pp.

Silva-Ortiz, I., Salgado-Soto, Z., 1988, Estudio estratigráfico estructural en la región de Tlalpujahua - El Oro, Edos. de Michoacán y México: Instituto Politecnico Nacional, Tesis de Licenciatura, 74 pp.

Smart, R., Skinner, W.M., Levay, G., Gerson, A.R., Thomas, J.E., Sobieraj, H. Schumann, R., Weisener, C.G., Weber, P.A., Miller, S.D., Stewart, W.A. 2002, ARD test handbook: project P387A, prediction and kinetic control of acid mine drainage: Melbourne, AMIRA International Ltd, $42 \mathrm{pp}$.

Talavera, O., Yta, M., Moreno, R., Dótor A., Flores N. and Duarte, C., 2005, Mineralogy and geochemistry of sulfide-bearing tailings from silver mines in the Taxco, Mexico area to evaluate their potential environmental impact: Geofísica Internacional, 44(1), 49-64.

Uribe-Salas, J.A., 2008, Historia de la Minería en Michoacán: Morelia, Michoacán, Universidad Michoacana de San Nicolás de Hidalgo, Sociedad Mexicana de Mineralogía, Museo Tecnológico del Siglo XIX "Las Dos Estrellas", Morevallado Editores, $227 \mathrm{pp}$.

WHO (World Health Organization), 2015, Global Health Observatory data repository. International Health Regulations (2005) monitoring framework: disponible en <http://apps.who.int/gho/data/node.main IHR?lang=en>, consultado el 15 de junio de 2017.

Manuscrito recibido: agosto 13, 2017

Manuscrito corregido recibido: octubre 9, 2017

Manuscrito aceptado: octubre 12, 2017 